\title{
Comparative genome analysis of Bacillus spp. and its relationship with bioactive nonribosomal peptide production
}

\author{
A. Hamdache · R. Azarken - A. Lamarti • \\ J. Aleu • I. G. Collado
}

Received: 18 December 2012/ Accepted: 2 March 2013/Published online: 17 March 2013

(C) Springer Science+Business Media Dordrecht 2013

\begin{abstract}
Bacillus genus comprises an important number of species which produce a wide range of secondary metabolites displaying a broad spectrum of activity and great structural diversity. The genome sequences of an important number of species have been published and a large number of orphan genes reported. This review, covering all the literature in this field up to end of 2011, summarizes and compares the genetic potential of these organisms from the point of view of bioactive nonribosomal peptide production and their application as antibiotics, plant pathogen biocontrol, promotion of plant growth, etc. The biological and structural studies of the peptides isolated from Bacillus species are revised and some aspects of the biosynthesis of these metabolites and related compounds are discussed.
\end{abstract}

Keywords Bacillus genome - Nonribosomal · Ribosomal · Peptide $\cdot$ Antibiotic $\cdot$ Lipopeptide . Siderophore

\footnotetext{
A. Hamdache · A. Lamarti

Department of Biology, Faculty of Sciences, University of Abdelmalek Essaadi, 2121 Tétouan, Morocco

R. Azarken · J. Aleu ( $₫)$ · I. G. Collado ( $\square)$ Departamento de Química Orgánica, Facultad de Ciencias, Universidad de Cádiz, Apdo. 40, 11510 Puerto Real, Cádiz, Spain

e-mail: josefina.aleu@uca.es

I. G. Collado

e-mail: isidro.gonzalez@uca.es
}

\section{Introduction}

Natural products continue to represent an excellent source of lead structures for drug discovery. Traditional methods used to isolate microbial natural products usually involve the collection and cultivation of strains, extraction, bioassay-guided isolation and structure elucidation. Unfortunately, this approach is often frustrating because of a high rediscovery rate. Thus, new concepts are required to increase the probability of discovering new bioactive structures (McAlpine et al. 2005).

However, an ever greater understanding of microbial genomics has provided valuable insights into the principles of natural product biosynthesis offering promising alternatives for the discovery and engineering of new chemical entities. The post-genomic world has shown that the traditional culture-based, bioassayguided strategies used to discover natural products only provided access to a small fraction of the biosynthetic capacity encoded in genomes. We now know that most biosynthetic pathways are not expressed at all, or just barely, under laboratory conditions, or the products of these pathways have simply been overlooked (Udwary et al. 2007).

Recent whole-genome sequencing programmes have revealed that the biosynthetic potential of microorganisms has been greatly underexplored, relying as it does on traditional approaches. In fact, the number of genes encoding biosynthetic enzymes in various bacteria and fungi clearly outnumbers the 
known secondary metabolites of these organisms (Challis 2008).

Bacillus represents just a small fraction of a larger taxonomic consortium of endospore-producing bacteria referred to as Bacillus sensu lato. The Bacillus genus comprises a very large, diverse set of Grampositive bacteria that have one common yet distinct feature: the ability to aerobically produce dormant endospores when challenged by unfavorable growth conditions. Thus, Bacilli are endospore-forming bacteria that are characterized by their rod-shaped cell morphology, catalase production and their ubiquitous distribution (Zeigler and Perkins 2009; Logan et al. 2007).

Members of the Bacillus genus are bacteria that exploit a wide variety of organic and inorganic substrates as nutrient sources. This ability to survive and grow in such diverse ecosystems is based on the production of robust endospores, their diverse physiological properties, especially the production of antibiotic molecules, and their growth requirements.

Bacilli are often thought of as microbial factories given their production of a wide array of biologically active molecules whose purpose it to suppress competitive bacteria and fungi in plants (Stein 2005), including peptide and lipopeptide antibiotics and bacteriocins. Furthermore, a wide number of complete and draft genome sequences are now available and Bacillus may very well be one of the best chemically characterised and most represented genera in the genomic databases.

\section{An overview of Bacillus sensu lato genus and its genome sequences}

The Bacillus sensu lato genus is both taxonomically and metabolically diverse. Their production of antimicrobial substances and sporulation capacity give Bacillus strains a dual advantage in terms of their survival in different habitats. They are phenotypically and genotypically heterogenous (Slepecky and Hemphill 2006), and consequently they exhibit quite diverse physiological properties such as the ability to break down many different substrates derived from plant and animal sources, including cellulose, starch, proteins, agar, hydrocarbons and even biofuels (Zeigler and Perkins 2009). Bacilli isolated from a wide range of environments, including plants and soil (Kunst et al.
1997; Priest 1993), hydrothermal vents (Takami et al. 2004), extreme environments (Rey et al. 2004; Takami et al. 2000), sea water (Siefert et al. 2000), and a shallow water column from an oligotrophic environment (Alcaraz et al. 2008) have been reported. The presence of Bacillus in these different environments brears witness to the broad metabolic capabilities of this widely distributed genus.

Their primary habitat is the soil and associated plants (B. amyloliquefaciens), rivers and estuarine waters (B. coahuilensis), and they are well known for their ability to control plant diseases through various mechanisms, including the production of secondary metabolites (Chen et al. 2009a). However, some species are pathogenic to mammals (e.g. B. anthracis) and insects (e.g. B. sphaericus, B. thuringiensis) (Wipat and Harwood 1999).

As Bacillus spp. are characteristically omnipresent in soils, exhibit high thermal tolerance and rapid growth in liquid culture, readily produce resistant spores and are considered to be a safe biological agent, their potential as a biocontrol agent is considered to be high (Shoda 2000). Additionally, their uses in insect control, food industry, livestock and environmental applications have been reported (Harwood and Cranenburgh 2008).

The genomic sequences of several Bacillus species have been made available over the last several years. Recent research has identified biosynthetic genes that code for a secondary metabolic pathway which are clustered in microbial genomes. This observation has facilitated their study and manipulation. Furthermore, greater insight has been gained into their pathways involving polyketide synthase (PKS) and nonribosomal peptide synthetase (NRPS) assembly lines which are responsible for the biosynthesis of these two large classes of natural products (Marahiel 1992; Calderone et al. 2006; Marahiel et al. 1993, 1997).

Recently, an interesting study, including a phylogenetic tree (Alcaraz et al. 2010), was carried out using whole genome information to reconstruct their evolutionary history taking advantage of the data set from the complete and draft genomes of twenty Bacillus isolated from a wide range of habitats, including a newly sequenced Bacillus isolated from an aquatic environment (Alcaraz et al. 2010).

An important number of projects are under way which will contribute to a better understanding of their ecological adaptations so as to be able to correlate 
particular sets of genes with their pathogenic potential and the production of bioactive peptides and metabolites in general (Ravel and Fraser 2005).

\section{Bacillus genus: comparative analysis of Bacillus genome}

The rate at which entire microbial genomes are being sequenced has grown rapidly over the past years and is revolutionising our understanding of microbial molecular biology and genetics.

As already indicated, bacilli can be subgrouped according to their ecophysiology (acidophily, alkaliphily, halophily, psychrophily and thermophily) and in terms of their metabolic diversity, into three major classes: pathogenic, environmental uses and industrial uses (Ravel and Fraser 2005). B. anthracis, B. cereus and $B$. thuringiensis represent the pathogenic group, while that the environmental bacilli are quite diverse and include B. subtilis, B. amyloliquefaciens, $B$. coahuilensis and B. halodurans. As for the class, the most representative strains with industrial applications are B. licheniformis and B. clausii. While this classification is useful in characterizing the metabolic diversity of the genus, it provides no guidance for a phylogenetic classification of the Bacillus for research purposes (Alcaraz et al. 2010). Thus, four groups of bacilli were defined following a classification system based on orthologous relations among genes: (a) $B$. anthracis-cereus-thuringiensis, (b) B. subtilis-licheniformis-pumilus, (c) B. clausii-halodurans, and (d) B. coahuilensis (Alcaraz et al. 2010).

Comparative analysis of the genome sequence of the related environmental isolates clearly shows that B. amyloliquefaciens, B. subtilis and B. licheniformis are closely related and quite distinct from the $B$. cereus group of organisms (B. anthracis, B. cereus and B. thuringiensis). Despite a high degree of chromosomal similarity among these genomes, significant differences in cell wall and spore coat proteins that contribute to the survival and adaptation in specific hosts were identified (Anderson et al. 2005).

Bacillus clausii-halodurans form the group of alkalophiles and halotolerant strains. Interestingly, this group has a fewer than average number of genes involved in the cell wall/membrane/envelope category. Additionally, there are several known differences in the cell wall composition of $B$. clausii-halodurans compared to B. subtilis, such as the presence of the major cell wall component teichurono-peptide (Takami et al. 2000).

\section{Pathogenic Bacilli group}

Bacillus anthracis, B. cereus, and B. thuringiensis are genetically very closely related, a fact which has led to a proposal for their consideration as a single species (Radnedge et al. 2003) but no consensus has been reached in this regard. This ambiguous taxonomic state of the B. cereus group illustrates the difficulties encountered in species definition within bacterial systematics, especially in the genomic era.

Several interesting reviews and papers have recently been reported on comparative genome analysis of the B. cereus group (Rasko et al. 2005; Read et al. 2002, 2003; Ivanova et al. 2003). The analysis of representative members of Bacillus genomes has led to the discovery of the shared and singular metabolic and virulence capability of each species. The presence of specific genes with functions related to spore coat, exopolysaccharide biosynthesis and membrane transport has revealed significant differences despite the high level of chromosomal similarity among B. cereus group bacteria. In this regard, recent studies have demonstrated differences in gene order, chromosomal rearrangements, nucleotide variations and remnant phages, suggesting that $B$. anthracis diverges from $B$. cereus and $B$. thuringiensis and represents a distinct genetic lineage(Read et al. 2002).

\section{B. cereus}

Discussion of the classification of B. cereus group strains is not only of academic and taxonomic interest, but is also important from a public health perspective because genes encoding the cytotoxins associated with diarrhoeal disease and other opportunistic B. cereus infections are generally chromosomally encoded and are present in all species of the B. cereus group, although they are silent in B. anthracis (Arnesen et al. 2008). B. cereus is frequently isolated as a contaminant of a number of foods and can occasionally be an opportunistic human pathogen (Helgason et al. 2000; Drobniewsk 1993). Thus, B. cereus isolates harbouring $B$. anthracis virulence factors have been detected in cases of severe anthrax-like illnesses (Hoffmaster et al. 2004). 


\section{B. anthracis}

Bacillus anthracis is a potent mammalian pathogen and potential bioterrorist agent which shares so much genetic material with $B$. cereus and $B$. thuringiensis that it is difficult to distinguish it from the other species. All three Bacillus species are prevalent in many environments and considerable efforts have been made to define the genetic differences specific to $B$. anthracis in order to design specific DNA-based identification protocols. Thus, a great many comparative analyses of $B$. anthracis to closely related bacteria genome sequences and comparative genome studies of B. cereus with B. subtilis and B. anthracis genomes have been performed by many scientists (Read et al. 2002, 2003; Ivanova et al. 2003; Keim et al. 2009).

A detailed comparative analysis of the genomes of B. cereus and B. anthracis revealed a small subset of genes unique to either species (Rasko et al. 2005). The majority of these genes are located at the terminus of replication, indicating that genome plasticity mostly occurs in that region. These data suggest a history of insertion and/or deletion in the evolution of the $B$. cereus group. It was observed that, in many cases, genes found at a specific position in one genome were replaced with others at the corresponding loci in another (Rasko et al. 2005).

\section{B. thuringiensis}

Bacillus thuringiensis is the most well-known and thoroughly studied example of an entomopathogenic bacterium which produces parasporal protein crystals in association with spore formation (Bode 2009). These protein toxins lyse the insect after ingestion (Zhou et al. 2008). Therefore natural and genetically engineered strains of $B$. thuringiensis have been used commercially to control pests of many representatives of the Lepidoptera, Diptera, and Coleoptera orders. Thus, B. thuringiensis has been widely exploited in agriculture as an insecticide, thanks to the presence of plasmid-borne crystal toxin genes (Schnepf et al. 1998).

Virulence against insects is believed to be conferred by multiple factors and the genomic sequence has identified numerous secondary metabolite gene clusters that could also contribute to the insecticidal activity of B. thuringiensis (Rasko et al. 2005).

Additionally, the genes encoding the Bt-toxins have been successfully transferred into cotton, corn, soybean, and rice conferring resistance to insect pests thus leading to a significant economic benefit (Zhou et al. 2008). Besides protein toxins, B. thuringiensis is also a producer of an acyl homoserine lactone lactonase which can eliminate the pathogenicity of plant pathogenic bacteria, and zwittermicin, a potent antibiotic and antifungal compound (Kevany et al. 2009).

Furthermore, the complete genome sequence of several strains of $B$. thuringiensis, such as B. thuringiensis Al Hakam (Challacombe et al. 2007) and $B$. thuringiensis BMB171 (He et al. 2010), has been reported. A comparative analysis of the genomes of both strains of $B$. thuringiensis has been described (see Table 1).

\section{Environmental Bacilli group}

The bacterium B. subtilis was first described in 1872 by Ferdinand Cohn and is a species that is second only to Escherichia coli in terms of the level of detail at which it has been studied (Ravel and Fraser 2005).

The $B$. subtilis group includes the most intensively studied of the bacilli, including species such as $B$. subtilis itself, B. amyloliquefaciens and B. licheniformis which are of industrial importance (Harwood 1992), and B. coahuilensis, one of the most recent Bacillus species reported from a marine environment (Cerritos et al. 2008).

\section{B. subtilis}

Bacillus subtilis has been a paradigm for the genetics of Gram-positive bacteria for more than 30 years. It

Table 1 Genomic properties of B. thuringiensis

\begin{tabular}{lllllll}
\hline Species & Strain & Genome size $(\mathrm{Mb})$ & $\%$ GC & No. of protein-coding genes & No. of tRNAs & No. of rRNA operons \\
\hline B. thuringiensis & Al Hakam & 5.31 & 35 & 4,969 & 105 & 13 \\
& BMB171 & 5.64 & 35.3 & 5,088 plus 276 on plasmids & 104 & 14 \\
\hline
\end{tabular}


has a particularly well-developed natural transformation system that proved invaluable for genetic manipulation and analysis in the pre-recombinant DNA technology era.

The $B$. subtilis genome sequence is the first complete genome of a free-living soil and rhizosphere bacterium which was accomplished by an international consortium of 46 laboratories worldwide (Kunst et al. 1997; Stewart et al. 2009). Its genome, composed of $4,214,810$ base pairs comprises 4,100 proteincoding genes. Of these protein-coding genes, $53 \%$ are represented once while a quarter of the genome corresponds to several gene families that have been greatly expanded by gene duplication. The identification of five signal peptidase genes, along with several genes for components of the secretion apparatus (Tjalsma et al. 1997) is important given the capacity of Bacillus strains to secrete large amounts of industrially important enzymes. Many of the genes are involved in the synthesis of secondary metabolites, including antibiotics. The genome contains at least ten prophages or remnants of prophages, indicating that bacteriophage infection has played an important evolutionary role in horizontal gene transfer, in particular in the propagation of bacterial pathogenesis (Kunst et al. 1997).

Data derived from the genome sequence (Moszer 1998) and the systematic functional analysis programme (Hunt et al. 2006), together with the wealth of knowledge already available for this organism, has opened the door to new opportunities in studying the behaviour and ecology of this soil and plant growthpromoting rhizobacterium at the molecular level.

\section{B. amyloliquefaciens}

Bacteria that are associated with plant roots and exert beneficial effects on plant development are referred to as plant growth-promoting rhizobacteria (Kloepper et al. 1980). They competitively colonize plant roots and can simultaneously act as biofertilizers and as antagonists (biopesticides) of recognized root pathogens including bacteria, fungi and nematodes. There is a large body of literature reporting the potential use of rhizosphere-associated bacteria in stimulating plant growth and biocontrol agents (Argüelles-Arias et al. 2009; Somers et al. 2004; Lugtenberg and Kamilova 2009). Among these, several strains belonging to the
Bacillus genus, particularly to the $B$. subtilis and $B$. amyloliquefaciens species, were reported as being effective in the biocontrol of multiple plant diseases caused by soilborne (Leclere et al. 2005; Chen et al. 2009b) or post-harvest pathogens (Senghor et al. 2007; Yang et al. 2008; Kotan et al. 2009). Members of the Bacillus genus are thus among the beneficial bacteria mostly exploited as microbial biopesticides. Bacillusbased products account for approximately half of the commercially available bacterial biocontrol agents (Fravel 2005).

The plant root-colonizing B. amyloliquefaciens strain FZB42 is an environmental strain which is distinguished from the domesticated model organism B. subtilis 168 by its ability to stimulate plant growth and to suppress plant pathogenic organisms (Idriss et al. 2002).

Bacillus amyloliquefaciens FZB42 genome analysis revealed the presence of numerous gene clusters involved in synthesis of nonribosomally synthesized cyclic lipopeptides (Chen et al. 2009c) and polyketides (Chen et al. 2007; Koumoutsi et al. 2004) with proven antimicrobial action (Koumoutsi et al. 2007).

\section{B. coahuilensis}

Bacillus coahuilensis is a sporulating bacterium isolated from the water column of a desiccation lagoon in the Cuatro Ciénegas Basin (CCB) in the central part of the Chihuahan desert (Coahuila, Mexico). A major question yet to be answered is whether bacteria from CCB are ancient marine bacteria that adapted to an oligotrophic system poor in $\mathrm{NaCl}$, rich in sulfates and with extremely low phosphorus levels. The B. coahuilensis genome is the smallest genome of a Bacillus species (3.35 Megabases) sequenced to date and provides insights into the origin, evolution, and adaptation of B. coahuilensis to the CCB environment. The size and complexity of the B. coahuilensis genome reflects the adaptation of an ancient marine bacterium to a novel environment, providing support for a "marine isolation origin hypothesis" that is consistent with the geology of CCB. This genomic adaptation includes the acquisition, through horizontal gene transfer, of genes involved in phosphorous utilization efficiency and adaptation to particularly luminous environments (Alcaraz et al. 2008). 
Industrial uses Bacilli group

\section{B. licheniformis}

Bacillus licheniformis is a Gram-positive, sporeforming bacterium widely distributed in the environment as a saprophytic organism. There are numerous commercial and agricultural uses for B. licheniformis and its extracellular products (Erickson 1976).

Bacillus subtilis and B. licheniformis are closely related species that feature similar saprophytic lifestyles in soils. Both species are known for their ability to secrete numerous proteins into the surrounding medium, some in quite high amounts (Voigt et al. 2006). This enables them to break down a variety of high molecular weight substances found in soils and use the resulting products as nutrients to sustain growth or to ensure their survival under scarce nutrient conditions. In addition, the ability to secrete large amounts of proteins has been exploited by the fermentation industry for some time now, especially for the production of industrial enzymes including several proteases, $\alpha$-amylase, penicillinase, pentosanase, cycloglucosyltransferase, $\beta$-mannanase and several pectinolytic enzymes (Erickson 1976).

A comparative study of the genome sequence of $B$. licheniformis with related environmental isolates clearly shows that $B$. licheniformis is closely related to those of the B. subtilis group and is quite distinct from B. cereus group organisms (Rey et al. 2004).

Two similar strains of $B$. licheniformis (ATCC 14580 and DSM13) (Rey et al. 2004; Veith et al. 2004) were sequenced by two different groups and published one shortly after the other.

Bacillus subtilis and B. licheniformis share approximately $80 \%$ of their proteome. However, there are notable differences in the numbers and locations of prophages, transposable elements and a number of extracellular enzymes and secondary metabolic pathway operons that distinguish these species.

Bacillus licheniformis uses cellulose as it sole source of carbon and energy. Additionally, B. licheniformis codes for activities that enable growth on a broad range of polysaccharides, particularly advantageous in the competitive soil environment and also of interest for biotechnological applications. Many new genes of potential interest for biotechnological applications were found in B. licheniformis; candidates include proteases, pectate lyases, lipases and various polysaccharide-degrading enzymes (Ravel and Fraser 2005).

\section{B. halodurans}

Generally, alkaliphilic Bacillus strains cannot grow or grow poorly under neutral $\mathrm{pH}$ conditions, but grow well at $\mathrm{pH}>9.5$. The complete genomic sequence of the alkaliphilic bacterium, strain B. halodurans $\mathrm{C}-125$, has been determined (Takami et al. 2000) and its genome compared with that of $B$. subtilis.

Alkaliphilic bacteria studies are focused on the enzymology, physiology and molecular genetics of these microorganisms to elucidate their mechanisms of adaptation to alkaline environments. Industrial applications of these microbes have been investigated and some enzymes, such as proteases, amylases, cellulases, and xylanases, have been commercialized (Takami et al. 2000).

\section{B. clausii}

Bacillus clausii is a facultative alkalophilic bacillus which is commercially used in the production of alkaline proteases for detergents (Saeki et al. 2007), and as a probiotic (Bozdogan et al. 2003) administered to humans to prevent the gastrointestinal side-effects caused by oral antibiotic therapy. Ingestion of high quantities of spores is thought to restore an intestinal flora following the destruction of normal flora by antibiotics.

Over the last years an important number of papers and reviews on the proteomics of the Bacillus genus have appeared providing insights into how proteomics can be used to bring the virtual life of genes to the real life of proteins (Hecker and Voelker 2004).

\section{Peptide metabolites from Bacillus spp.}

Bacillus species produce a wide array of biologically active molecules including polyketides, lipopeptides, siderophores and peptides. Polyketides (Hamdache et al. 2011) are beyond the scope of this review, which focuses more specifically on nonribosomal bioactive peptides.

Nutritional stress conditions lead to the activation of a number of processes affecting survival rate. Activities induced include the development of genetic 
competence, sporulation, and synthesis of degradative enzymes, motility, and antibiotic production. The genes that function in these processes are activated during the transition from exponential to stationary phase and are controlled by mechanisms that operate primarily at the level of transcription initiation (Jedrzejas and Huang 2003).

From the point of view of biosynthesis, Bacillus genus species produce two different classes of peptides: ribosomal and nonribosomal peptides, which are biosynthesized by two different biosynthetic pathways allowing the incorporation of such unusual (nonproteinaceous) constituents: (a) the nonribosomal synthesis of peptides by large megaenzymes, nonribosomal peptide synthetases (NRPSs) and (b) the ribosomal synthesis of linear precursor peptides that are subjected to post-translational modification and proteolytic processing.

\section{Ribosomal bioactive peptides}

Bacterial antimicrobial peptides produced by ribosomal synthesis are commonly referred to as bacteriocins. This is a heterologous group of proteinaceous antimicrobial substances produced by bacteria from every major lineage. They display a high degree of target specificity against related bacteria although many have a wider spectrum of activity (Abriouel et al. 2011).

Unlike nonribosomal peptides (NRPs), ribosomal peptide (RP) natural products are unable (as far as is known) to explore amino acids beyond the canonical 20 proteinogenic amino acids, limiting their structural diversity to some degree. However, they can be extensively post-translationally modified and such modifications give rise to products with many features resembling those of NRPs. In fact, many of the modifications commonly thought of as "nonribosomal" are also found in ribosomally synthesized peptides. Other RPs has unique modifications that allow them to explore greatly expanded chemical spaces in a manner similar to the NRPs (McIntosh et al. 2009).

A great advantage of the RPs is that their sequences may be modified by simple manipulation of a few codons in contrast to NRPs which require extensive genetic engineering to incorporate changes. Thus, ribosomal natural products have many -but not all- of the structural advantages of the NRPs, and in addition they are easier to modify to produce novel bioactive compounds. Many excellent reviews of individual RP classes have recently come out such as lantibiotics, microcins and others. Especially relevant is the one concerning bacteriocines recently published by A. Gálvez et al. (Abriouel et al. 2011).

Furthermore, the number of known peptide natural products that are synthesized via the ribosomal pathway has grown rapidly and their remarkable structural and functional diversity may lead to novel pharmaceutical applications. The strategies used for the identification of these ribosomally synthesized and posttranslationally modified peptides (RiPPs) and the structures of newly identified compounds have recently been reviewed (Velasquez and van der Donk 2011). The reader is referred to these reviews for a more in-depth look at individual RP classes.

The number of RP families has increased considerably in recent years with the discovery of the biosynthetic origin of cyanobactins, thiopeptides, microviridins and amatoxins. These findings have shown that the ribosomal world is much more diverse than originally thought, and have revealed an enormous structural diversity that is just beginning to be appreciated (McIntosh et al. 2009; Oman and van der Donk 2010).

\section{Nonribosomal bioactive peptides}

Nonribosomal peptides are a structurally diverse class of peptides with various functions, such as cytostatic, immunosuppressive, antibacterial, or antitumor properties. These secondary metabolites differ from peptides of ribosomal origin in several ways. Their length is limited to a mere 20 building blocks, roughly, and mostly a circular or branched cyclic connectivity is found. Furthermore, aside from the proteinogenic amino acids, a larger variety of chemical groups is found in these bioactive compounds: D-configurated amino acids, fatty acids, methylated, oxidized, halogenated, and glycosylated building blocks. These functional and structural features are known to be important for bioactivity, and often natural defense mechanisms are thus evaded (Schoenafinger and Marahiel 2009).

The genes encoding the multifunctional enzymes that catalyse nonribosomal synthesis of the peptide antibiotics are organized in operons that are transcriptionally induced in response to nutritional stress. The regulation of antibiotic biosynthesis operons is accomplished through the interaction of diverse factors 
which also function in controlling other stationaryphase-induced processes in Bacillus. Peptide antibiotic biosynthesis genes are regulated by factors as diverse as the early sporulation gene product SpoOA, the transition-state regulator $\mathrm{AbrB}$, and gene products (ComA, ComP, and ComQ) required for the initiation of the competence developmental pathway (Marahiel et al. 1993).

In spite of their structural heterogeneity, the nonribosomal peptide antibiotics are biosynthesized by the iterative coupling of amino acids and share a common mode of synthesis, the multicarrier thiotemplate mechanism which is carried out by the large multidomain enzymatic machineries, the so-called nonribosomal peptide synthetases (NRPSs). NRPS are megaenzymes organized in iterative functional units called modules that catalyze the different reactions leading to polyketide or peptide transformation. The first crystal structure of an entire module of domains from an NRPS system has recently been reported (Weissman and Mueller 2008). These megasynthetases build the growing chains as a series of elongating acyl-S-proteins, covalently tied to the terminal thiol of phosphopantetheinyl arms, with themselves hitched to side chains of serine residues of carrier protein domains in the assembly line (Fischbach and Walsh 2006; Walsh 2008).

Each module is subdivided into several catalytic domains responsible for each biochemical reaction. A typical NRPS module usually comprises 1,000 amino acid residues approximately and is responsible for one reaction cycle. Each elongation cycle in nonribosomal peptide biosynthesis needs the cooperation of three basic domains:

(a) adenylation domain, which generates an enzymatically stabilized aminoacyl adenylation.

(b) peptidyl carrier domain, which transfer and bound the adenylated amino acid substrate by a thioester bond.

(c) condensation domain catalyzes formation of a new peptide bond. The linear organization of such core units $(\mathrm{a}-\mathrm{c})$ ensures the coordinated elongation of the peptide product. The basic set of domains within a module can be extended by substrate modifying domains, including domains for substrate epimerization, hydroxylation, methylation and heterocyclic ring formation, which act as independent catalytic units (Finking and Marahiel 2004).
Three major chemical routes for disconnection of the covalent thioester linkages of NRPS acyl chains when they reach the most downstream carrier protein domains on assembly lines have been observed. A thioesterase domain, which in some cases is responsible for the cyclization of the peptide, is usually present in the last module to ensure the cleavage of the thioester bond between the emerging peptide and the last PCP domain (Walsh 2008).

The logic of NRPS assembly lines is modular (Marahiel et al. 1997), and the encoding genes in microbial genomes are almost always clustered. The molecular organization of these peptides synthetases and the regulation of the corresponding biosynthesis genes have been analyzed and reported (Marahiel et al. 1993). This basic mechanism can result in great chemical variety of peptide products containing hydroxy-, L-, D-, or unusual amino acids, which can be further modified by $\mathrm{N}$ methylation, acylation, glycosylation or heterocyclic ring formation. More than 300 different residues are known to be incorporated into these peptide secondary structures (Hancock and Chapple 1999).

The therapeutic potential of peptides of nonribosomal origin is well recognized. In addition, recent years have seen the discovery of a growing number and wide diversity of peptides that are biosynthesized by a nonribosomal pathway (Frueh et al. 2008).

However, in spite of the high number, wide structural diversity and growing number of nonribosomal peptides, to our knowledge no classification scheme has been devised for this class of Bacillus peptides. This is probably a result of the confusing information about structures of some reported peptides, lack of information on many of these peptides amino acid sequences or the vast diversity of nonribosomal peptides produced by bacilli. This review has been organized on the base of the peptides/amino acid sequences molecular structure point of view. Two major groups can be differenced, cyclic and linear peptides, and both groups have been arranged on the base of the structure-peptides number.

\section{Cyclic peptides}

\section{Tridecapeptides}

The antifungal peptide antibiotic, mycobacillin (1) (Fig. 1), was isolated from the $\mathrm{B}_{3}$ strain of B. subtilis. The study of the physicochemical properties of 
Fig. 1 Trideca-, dodecaand undecapeptides reported from Bacilli

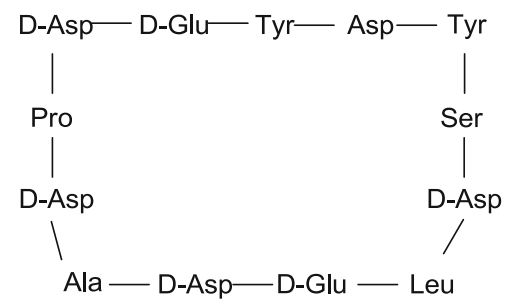

1

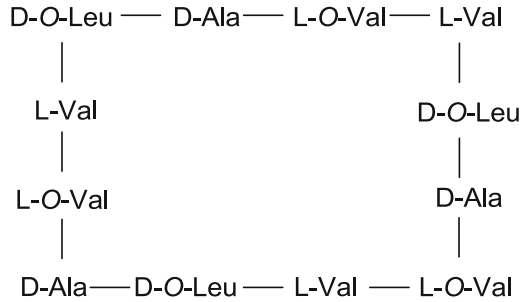

2

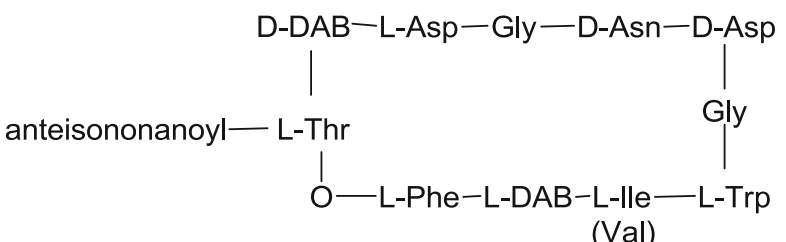

3

mycobacillin (1) shows that it is a polypeptide consisting of five aspartic acid residues, two glutamic acid and two tyrosine residues and one residue each of serine, alanine, leucine and proline (Majumdar and Bose 1960).

The biosynthesis of the cyclic mycobacillin (1) is an alternative to the thiotemplate mechanism of peptide antibiotic biosynthesis. Instead of two-step activation of amino acids, a single-step mechanism with formation of aminoacylphosphate was proposed. The enzyme complex that catalyzes the synthesis of mycobacillin (1) is separated into three fractions: (A) which operates during synthesis of the first pentapeptide; (B) which catalyzes the synthesis of the nonapeptide; and (C) which catalyzes synthesis of the final product (Mannanov and Sattarova 2001).

\section{Dodecapeptides}

Cereulide (2) (Fig. 1), is a cyclic dodecadepsipeptide produced by $B$. cereus which acts as a potassium ionophore. Cereulide (2), an emetic toxin, is heat, acid and alkaline stable as well as resistant to proteolysis by trypsin and pepsin, making it of particular concern to the food industry, as existing emetic toxin is not inactivated by processing methods (Ehling-Schulz et al. 2004). The emetic syndrome is usually characterized by nausea and vomiting, however, more severe cases have also been reported, leading for instance to acute liver failure (Posfay-Barbe et al. 2008).

In light of the increasing number of serious food borne outbreaks caused by emetic B. cereus, transcriptional kinetic analyses of cereulide synthetase genes with respect to growth, sporulation and emetic toxin production have been reported (Dommel et al. 2011).

Cereulide (2) is closely related to the antibiotic valinomycin (Agata et al. 1994). Both compounds are known as $\mathrm{K}^{+}$-ionselective ionophores and cause a potassium-dependent drop in the transmembrane potential of mitochondria arising from the uptake of a $\mathrm{K}^{+}$-ioncharged ionophore complex (Makarasen et al. 2009). The cereulide peptide synthetase of the emetic B. cereus reference strain $\mathrm{F} 4810 / 72$ was found to be located on a pXO1-like plasmid, designated pBCE, and was identified as a $24 \mathrm{~kb}$ ces gene cluster comprising seven codingDNA sequences(EhlingSchulz et al. 2006).

Homocereulide, isolated from the marine bacterium B. cereus SCRC, is very similar to cereulide (2). It differs only in the presence of a methyl group. Thus, the stereochemistry of homocereulide was deduced to be cyclo[-(D-Hic-D-Ala-L-Hiv-L-Val-) $)_{2}$-D-Hic-D-AlaL-allo-Hmv-D-Val-]. Both homocereulide and cereulide (2), exhibited extremely potent cytotoxicity and activity against the murine leukemia cell line P388 and the colon 26 tumor cell line (Sheng et al. 1995).

\section{Undecapeptides}

In 1976, Shoji et al. (1976a) reported the isolation of an amphoteric acylpeptide antibiotic named brevistin (3) (Fig. 1) from the culture broth of B. brevis 342-14 which is active against Gram-positive bacteria in vitro and in vivo. Brevistin (3) is thought to be a complex of undecapeptides, consisting of a major peptide (80\%) 
containing isoleucine and a minor $(20 \%)$ containing valine: isoleucine or valine is present in the same position of the sequence. The constituent fatty acid was elucidated to be anteisononanoic acid by gas chromatography-mass spectrometry (Shoji and Kato 1976a).

Esein and bresein are two cyclopeptides produced by B. brevis (Zharikova et al. 1975). Esein is amphoteric and has one free $\mathrm{NH}_{2}$ group and 11 amino acids (Radzhapov et al. 1968). Bresein is basic and it has two $\mathrm{NH}_{2}$ groups. The biosynthesis of these antibiotics was studied in different media (Kherat et al. 1974).

\section{Decapeptides}

\section{Lipodecapeptides}

\section{Fengycin and related compounds}

Bacillus strains produce a broad spectrum of bioactive nonribosomal lipopeptides with great potential for biotechnological and biocontrol applications and include lipopeptides of the iturin, surfactin and fengycin families. All these lipopeptides feature a lipophilic fatty acid chain and a hydrophilic peptide ring and exhibit powerful biocontrol activities (Touré

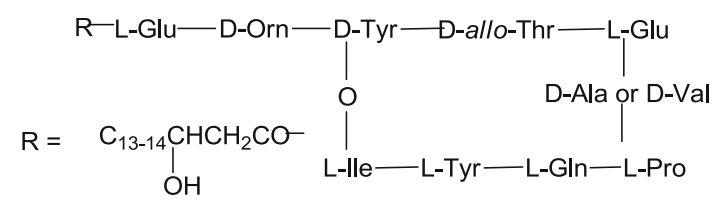

4

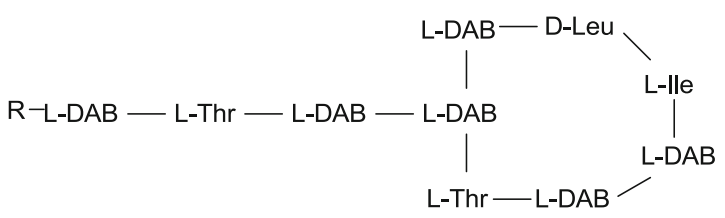

$\mathrm{R}=\mathrm{CH}_{3} \mathrm{CH}_{2} \mathrm{CH}\left(\mathrm{CH}_{3}\right)\left(\mathrm{CH}_{2}\right)_{4} \mathrm{CO}-$

6
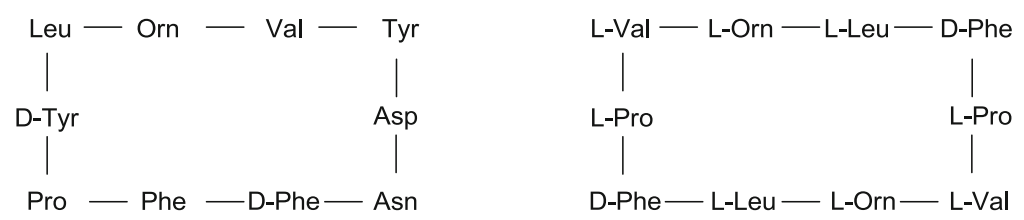

9 et al. 2004). They are amphiphilic cyclic peptides composed of $7 \alpha$-amino acids (surfactins and iturins) or $10 \alpha$-amino acids (fengycins) linked to one unique $\beta$-amino fatty acid (iturins) or $\beta$-hydroxy fatty acid (surfactins and fengycins). The length of the fatty acid chain varies from $\mathrm{C}_{13}$ to $\mathrm{C}_{16}$ for surfactins and from $\mathrm{C}_{14}$ to $\mathrm{C}_{17}$ for iturins. Lipopeptides have low toxicity, high biodegradability and are environmentally friendly compared with chemical pesticides. Furthermore, some lipopeptides show great promise as antitumour, antiviral and antimycoplasma agents (Yang et al. 2006).

Fengycin (4) and the closely related plipastatin (Fig. 2) are cyclic lipodecapeptides containing a $\beta$-hydroxy fatty acid with a side chain length of $16-19$ carbon atoms. Four D-amino acids and ornithine (a non-proteinogenic residue) have been identified in the peptide portion of fengycin (4). It is specifically active against filamentous fungi and inhibits phospholipase $\mathrm{A}_{2}$ (Nishikiori et al. 1986a).

Fengycin (4) is a lipopeptide biosurfactant (Vater et al. 2002) produced by several Bacillus species. This

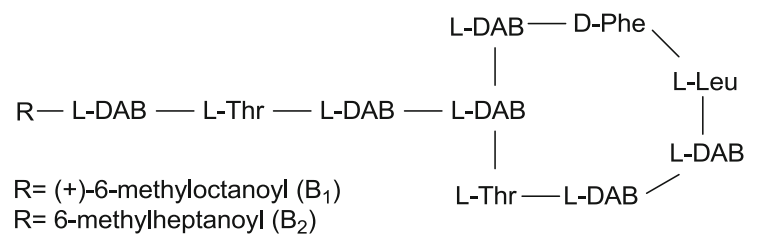

5
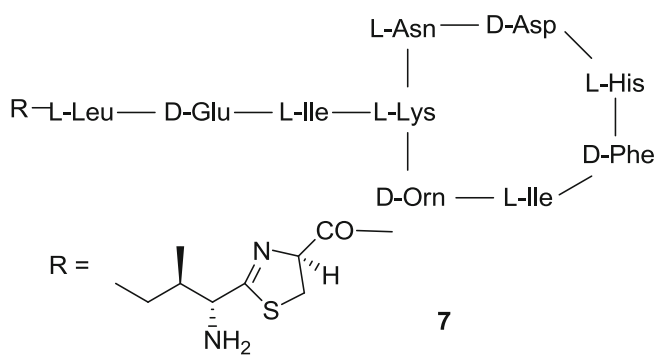

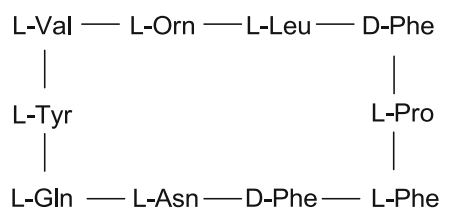

Fig. 2 Decapeptides 
lipopeptide can function as a biocontrol agent, and exhibits fungicidal, bactericidal, and insecticidal activity (Vanittanakom et al. 1986). It is known to develop antifungal activity against phytopathogen fungi and to exhibit hemolytic activity. Like most of the natural antimicrobial peptides, fengycin (4) likely acts by increasing the permeability of the target cell's plasma membrane (Deleu et al. 2008). The inhibition is antagonized by sterols, phospholipids and oleic acid, whereas two other unsaturated fatty acids increase the antifungal effect (Vater et al. 2002).

The plipastatins, isolated from B. subtilis (Tsuge et al. 1996, 1999) and B. cereus (Umezawa et al. 1986), are very similar to fengycins. They differ only in the stereochemistry of the Tyr residues (L to D diastereoisomers) (Volpon et al. 2000). The antimicrobial spectrum of plipastatins is still mostly unknown but was shown to inhibit the phospholipase $A_{2}$ (Umezawa et al. 1986), an enzyme involved in a number of physiologically important cellular processes such as inflammation, acute hypersensitivity and blood platelet aggregation (Hirata and Axelrod 1980). As for the other lipopeptides produced by $B$. subtilis, plipastatins are biosynthesised as a mixture of isoforms characterised by variations in both the nature of the hydrophobic tail and the amino acid composition (Nishikiori et al. 1986b). The hydrophobic tail is a $3(R)$-hydroxy hexadecanoic acid (plipastatins $\mathrm{A}_{1}$ and $\mathrm{B}_{1}$ ) or a 14(S)-methyl-3(R)hydroxy hexadecanoic acid (plipastatins $\mathrm{A}_{2}$ and $\mathrm{B}_{2}$ ) while the amino acid sequence differ in position 6 with a D-Ala (plipastatin $A_{1}$ and $A_{2}$ ) substituted by a D-Val (plipastatin $\mathrm{B}_{1}$ and $\mathrm{B}_{2}$ ) (Volpon et al. 2000).

Maltacines comprise a family of peptide lactone antibiotics related to fengycin (4), produced by a strain of $B$. subtilis, of which 13 of the molecules have been studied, B1a, B1b, B2a, B2b (Hagelin 2005a, 527-538), C1a, C1b, C2a, C2b (Hagelin 2005b, 1276-1286), D1a, D1b, D1c (Hagelin 2005c, 1287-1299), E1a and E1b (Hagelin 2005d). These are suggested to be cyclo-4,12 peptide lactones whose members have major parts of their primary sequences in common. Position 4 in all members was thought to be occupied by a hydroxyamino-acid that is part of the lactone ring (Hagelin et al. 2007). Maltacines present activity against Gram-positive bacteria such as Staphylococcus aureus, some Gram-negative bacteria and the opportunistic fungi Candida albicans, Tricophyton mentagrophytes and Aspergillus fumigatus (Hagelin, 2005d).

\section{Polymyxin family and related compounds}

Antimicrobial polycationic peptides have been isolated from a wide variety of species and include the microbial polymyxins (Vogler and Studer 1966). Polymyxins, including polymyxins A (Wilkinson and Lowe 1966), B (5), C (Charbonneau et al. 1998), D (Brownlee et al. 1949), E, F, M, T, $\mathrm{S}_{1}$ and P, are a wide family of closely related peptide antibiotics containing a cycloheptapeptide ring with a C-8 or C-9 fatty acid attached through an amide bond (Fig. 2) (Storm et al. 1977). These antibiotics are active against many Gram-negative and a few Gram-positive microorganisms (Newton 1956), but their mode of action is still not precisely known.

The cationic surfactant polymyxin B (5) (a mixture of polymyxins $\mathrm{B}_{1}$ and $\mathrm{B}_{2}$ ) is an $\alpha, \gamma$-diaminobutyric acid (DAB)-rich decapeptide from Paenibacillus polymyxa exhibiting antimicrobial and lipopolysaccharide (LPS)-antagonistic activities. It is effective against Gram-negative bacteria (Rosenberg and Ron 1999). Polymyxin B nonapeptide is a derivative of polymyxin B (5) (Bhattacharjya et al. 1997).

Polymyxin E, a mixture of polymyxins $\mathrm{E}_{1}$ and $\mathrm{E}_{2}$ isolated from $P$. polymyxa, designates a multicomponent branch of the polymyxin family that is commonly known as colistin. Polymyxin $\mathrm{E}_{1}$, the major constituent, is considered to be the active pharmaceutical ingredient for therapeutic indications. It contains one D-leucine, one L-leucine, six L- $\alpha, \gamma$-diaminobutyric acid, and two L-threonine residues. The cyclic structures of the polymyxins $\mathrm{E}_{1}$ and theirs analogs were selective for Gram-negative bacteria and showed potent inhibitory activity against $E$. coli and against Pseudomonas aeruginosa. In contrast, the acyclic analogs of these peptides showed no antimicrobial activity (Kline et al. 2001).

Polymyxin $\mathrm{F}$ is an antibiotic produced by $B$. circulans ATCC No 31228, which is comprised of 2,4-diaminobutyric acid (DAB), Thr, Ser, Ile and Leu at a ratio of $5: 1: 1: 1: 2$. The hydrolysate also contains three extractable fatty acids identified as 6-methyloctanoic acid, isooctanoic acid and octanoic acid, with relative abundances of 78:19:3, respectively. Polymyxin $F$ possesses a pattern of antimicrobial activity that is similar to that of polymyxin B (5) (Parker et al. 1977).

Mattacin (polymyxin M) possesses an amide linkage between the C-terminal threonine and the side chain amino group of the diaminobutyric acid residue 
at position 4. It contains an (S)-6-methyloctanoic acid moiety attached as an amide at the $\mathrm{N}$-terminal amino group, one D-leucine, six L- $\alpha, \gamma$-diaminobutyric acid and three L-threonine residues. Mattacin was capable of inhibiting the growth of a wide variety of Grampositive and Gram-negative bacteria, including several human and plant pathogens with activity comparable with purified polymyxin B (5), a commercial antibiotic (Martin et al. 2003).

Two members of the polymyxin group of antibiotics, named polymyxins $S_{1}$ and $T_{1}$, have been isolated from $B$. polymyxa Rs-6 and B. polymyxa E-12, respectively. These antibiotics are strong basic substances soluble in water, and are primarily active against Gram-negative bacteria in vitro and in vivo, though polymyxin $T_{1}$ exhibits somewhat higher activities against Gram-positive bacteria than other polymyxin group antibiotics do (Shoji et al. 1977a). In both polymyxins, $S_{1}$ (Shoji et al. 1977b) and $T_{1}$, the constituent fatty acid proved to be anteisononanoic acid. Another antibiotic complex, polymyxin $\mathrm{P}$, was also isolated from B. polymyxa T-39 (Kimura et al. 1969).

Circulins are a group of basic polypeptides related to polymyxins which are produced by $B$. circulans ATCC 14040 (Fig. 2) (Fujikawa et al. 1965). The isooctanoyl group is the terminal group of the sidechain. Circulin A (6) (Vaara and Vaara 2009) and circulin B are similar to polymyxin insofar as their ability to inhibit the growth of Gram-negative more strongly than Gram-positive bacteria, but have a somewhat different bacterial spectrum. They are inactivated by crude trypsin while polymyxin is not and are more toxic than polymyxin (Murray et al. 1949).

A strain of $B$. polymyxa (BP1), isolated from cauliflower seeds, inhibited the growth of microbial phytopathogens. Two antibacterial substances were isolated and purified from culture broth. The first compound was named gavaserin because it contained glutamic acid, alanine, valine, serine and 2,4-diaminobutyric acid, and octanoic acid. No fatty acid was detected in the second compound, which was named saltavalin because it contained serine, alanine, leucine, threonine, valine, and 2,4-diaminobutyric acid (Pichard et al. 1995).

\section{Bacitracin family}

Bacitracins are synthesized by certain strains of $B$. licheniformis or B. subtilis (Pfaender et al. 1973; Ming and Epperson 2002). Although several bacitracins have been described in the literature, the most thoroughly researched is bacitracin A (7), a cyclic decapeptide with four of the aminoacids (glutamic, ornithine, phenylalanine, and asparagine) in the D-configuration. The molecule contains a thiazoline ring structure and exhibits potent antibiotic activity against Gram-positive bacteria (Pavli and Kmetec 2006).

\section{Other decapeptides}

Microorganisms isolated from marine habitats have emerged as a promising source of new bioactive metabolites with potential for development into drugs for treating human diseases (Davidson 1995). Loloatins A (8) to D (Fig. 2) is a family of cationic cyclic decapeptide antibiotics isolated from a tropical marine B. laterosporus collected in Papua New Guinea. Loloatins exhibit in vitro antimicrobial activity against methicillin-resistant $S$. aureus, vancomycin-resistant enterococci, and drug-resistant Streptococcus pneumoniae (Gerard et al. 1999). In addition to being the most potent of the four family members, loloatin $\mathrm{C}$ is also the only one active against the Gram-negative strain E. coli, making it an interesting lead compound for further development towards broad spectrum antibiotics (Tuin et al. 2009).

The soil bacterium Aneurinibacillus migulanus (formerly known as B. brevis) secretes the antibiotic tyrothricin, a mixture of linear pentadecapeptides (gramicidins A, B, and C) and backbone-cyclized cationic decapeptides [gramicidin S (GS) (9) and tyrocidins] (Mogi and Kita 2009).

GS (9) is an extremely powerful antibiotic drug against a broad spectrum of both Gram-negative and Gram-positive bacteria (Kondejewski et al. 1996). Regrettably, 9 is very hemolytic which presently restricts its use to topical applications (Xu et al. 1995). GS (9) is also effective against several pathogenic fungi, and Otoguro et al. (1988) reported nematocidal activities of GS (9) and polymyxins against the pine wood nematode Bursaphelenchus lignicolus. The gramicidin S (9) was also studied for its efficiency in inhibiting insect larvae (Nickerson and Schnell 1983).

Gramicidin S (9) and tyrocidines produced by different strains of $B$. brevis share two identical sequences of five different amino acids. Studies in various laboratories have led to suggestions of a possible regulatory function of tyrocidines in the induction of sporulation through a selective inhibition of RNA synthesis during cell differentiation. Despite 
its structural similarity to tyrocidine, gramicidin S (9) does not inhibit RNA synthesis at the transcription level but does inhibit the uptake of RNA precursors during germination and, as a consequence, it may delay spore outgrowth (Danders et al. 1982).

Consecutive single amino acid substitutions of tyrocidin result in the $\mathrm{A}(\mathbf{1 0}), \mathrm{B}$ and $\mathrm{C}$ analogues (King and Craig 1955). Tyrocidin is active against Gramnegative bacteria and is used in a wide variety of pharmaceutical compositions such as dental care products, mouth wash, cough medicines and eyedrops.

Gramicidin S (9), tyrocidine A (10) and gratisin (GR) $\left.\left[\text { cyclo(-Val }{ }^{1}-\mathrm{Orn}^{2}-\mathrm{Leu}^{3} \text {-D-Phe }{ }^{4}-\mathrm{Pro}^{5} \text {-D-Tyr }{ }^{6}-\right)_{2}\right]$ (Fig. 2) are potent cyclopeptide antibiotics with the amphiphilic $\beta$-sheet conformation. In view of widespread resistance to antibiotics that has become a serious threat to public health, amphiphilic antibiotics are attractive targets for drug discovery. It has been proposed that the principal modes of antibiotic action result from an interaction of these antibiotics with the cell membrane of the target microorganisms. Moreover, so far no resistance to the antibiotics has been detected because it requires significant alteration of the lipid composition of the cell membrane. Gramicidin S (9) and tyrocidine A (10) have very high hemolytic activity, preventing their direct use in combating microbial resistance. However, gratisin showed significantly reduced toxicity against human blood cells and high antimicrobial activity thus proving to be a good drug candidate (Tamaki et al. 2009).

\section{Nonapeptides}

\section{Polypeptin-permetin family and related compounds}

The cyclic depsipeptide permetin A (11) is one member of the polypeptin-permetin family of antibiotics produced by $B$. circulans. The members of this family, polypeptin A, permetin A (11) and BMY-
28160 have closely related structure, they have the same $\beta$-hydroxyl fatty acid constituent and differ from one other only by one or two amino acids (Fig. 3) (Murai et al. 1985). Permetin A (11) was isolated from B. circulans AJ 3902 and showed activity in vitro against Gram-negative, Gram-positive and some anaerobic bacteria (Yoko et al. 1979).

In the course of screening for new antibiotics with broad antibacterial spectrum, B. circulans strain H913-B4 was found to produce a novel antibiotic coded as BMY-28160. Antibiotic BMY-28160 is active against Gram-positive and Gram-negative bacteria, anaerobes and fungi. BMY-28160 is closely related to permetin $\mathrm{A}(\mathbf{1 1})$, the difference being the $\mathrm{L}-$ valine content in place of $\mathrm{L}$-isoleucine in permetin $\mathrm{A}$ (11) (Sugawara et al. 1984).

Polypeptin, a basic peptide antibiotic isolated from B. circulans, contained 2 components, polypeptin A and polypeptin $\mathrm{B}$, which have identical amino acid components but varied in the structure of the hydroxy acid constituent attached to the $\alpha$-amino group of the peptide chain. Polypeptin A contained 3-hydroxy-4methylhexanoic acid and polypeptin B contained 3-hydroxy-5-methylhexanoic acid (Sogn 1976).

\section{Octapeptides}

Lipooctapeptides: octapeptin and related compounds

Octapeptins are antibiotics, all octapeptides acylated with a fatty acid residue, which differ with respect to the ratio and the chirality of the constituent amino acids and also in the nature of the fatty acid substituent. Most, if not all, are broad-spectrum antibiotics exhibiting good activity against $P$. aeruginosa (Meyers et al. 1976).

Octapeptins A and B, previously named EM49, have two different peptides: one comprised of five 2,4-diaminobutyric acid (DAB), one Phe, and two Leu residues and the other comprised of five $\mathrm{DAB}$ and three Leu residues. Each of these variants is acylated

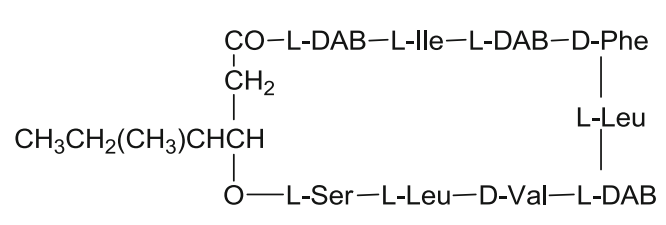

11

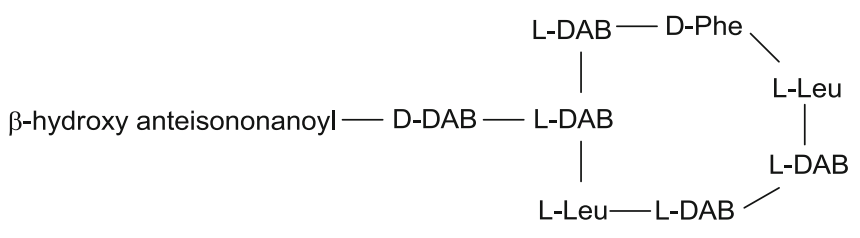

12

Fig. 3 Nona- and Octapeptides 
with a $\mathrm{C}-10$ or a $\mathrm{C}-11 \beta$-hydroxy fatty acid. Moreover, the EM49 antibiotics have been reported to have moderate activity against yeasts and filamentous fungi (Parker and Rathnum 1975). The antibiotic octapeptin $\mathrm{C}_{1}$ (12), previously named 333-25 (Shoji et al. 1976b), is an acylpeptide produced by a strain of $B$. circulans (Fig. 3). It is active against Gram-positive and Gramnegative bacteria (Kato and Shoji 1976).

Octapeptin D is another member of the octapeptin group of antibiotics, produced by Bacillus strain JP301 (Shoji 1978). Octapeptin D is assumed to be a complex of components which differ at the fatty acyl residue. It appears to be an octapeptide in which the $\gamma$-amino groups of the three DAB residues were uncovered and the $\mathrm{N}$-terminal amino groups were masked. Furthermore, a ring structure with a branched chain was also suggested in which one DAB residue was present at the branching point (Kato and Shoji 1980).

\section{Heptapeptides}

Lipoheptapeptides: iturins and surfactins families Iturin family

The iturin family is of great biotechnological and pharmaceutical interest. These are polar cyclic heptapeptides extracted from various strains of Bacillus spp. These compounds contain one $\beta$-amino fatty acid and seven $\alpha$-amino-acids with D-tyrosin as the second amino acid and two additional D-amino acids at positions 3 and 6 (Fig. 4) (Chen et al. 2009c). Numerous pharmacological properties have been reported for various iturins, including potent antifungal, antibiotic and antitumor activities (Trischman et al. 1994). They exhibit strong antifungal activities against a wide variety of pathogenic yeasts and fungi but their antibacterial activities are restricted to some bacteria such as Micrococcus luteus (Maget-Dana and Peypoux 1994). The iturin group contains iturins A, C, $\mathrm{D}$ and $\mathrm{E}$, bacillomycin D, F and L, bacillopeptin and mycosubtilin (Moyne et al. 2004).

Iturin A (13) is a cyclic lipopeptide produced nonribosomaly by several strains of Bacillus spp. with an aliphatic chain of the $\beta$-amino acid with 14 or 15 carbon atoms (Fig. 4) (Peypoux et al. 1978a). Compound 13 exhibits antibacterial activity on $M$. luteus (Maget-Dana and Peypoux 1994) but is more effective against fungi and yeasts, passing through the cell wall and disrupting the plasma membrane with the formation of small vesicles and aggregation of intramembranous particles (Thimon et al. 1995).
The antibiotic strength of iturin A (13) is related to change in the permeability of the membrane cells which leads to a leakage of $\mathrm{K}^{+}$from the intracellular medium (Harnois et al. 1989). It has recently been reported that iturin A (13) is the principal inhibitor in the biocontrol activity of $B$. amyloliquefaciens PPCB004 against postharvest fungal pathogens (Arrebola et al. 2010). In addition, the lipopeptide iturin A (13) is able to cause dose-dependent hemolysis in human erythrocytes (Aranda et al. 2005).

Iturin C, normally found together with iturin A (13), differs from it by the presence of an L-aspartyl residue linked to the carboxyl group of the $\beta$-aminoacid in spite of the L-asparaginyl residue in iturin A (13). In contrast to iturin A (13), iturin C exhibits no antibiotic activity (Peypoux et al. 1978b). Two novel metabolites with long chain $\beta$-amino acid moieties of different length were isolated from a strain of Bacillus sp. as inhibitors of oxidized low density lipoprotein (oxidized LDL) binding. These metabolites were shown to be related to the cyclic lipopeptide iturin C (Park et al. 1995).

Iturin $\mathrm{D}$ and iturin $\mathrm{E}$, isolated from a strain of $B$. subtilis producing iturin A (13), differ from iturin A (13) by the presence of a free carboxyl group in iturin $\mathrm{D}$ and a carboxymethyl group in iturin $\mathrm{E}$. Iturin $\mathrm{D}$ and iturin $\mathrm{E}$ exhibited strong antifungal activity against yeasts and fungi but failed to exhibit any antibacterial activity (Besson and Michel 1987).

Bacillomycin D (14), previously reported by Raubitschek and Dostrovsky (1950) as an antifungal crude preparation isolated from a strain of $B$. subtilis, was later classified in the iturin group (Besson et al. 1976). Bacillomycin D (14) is a mixture of two homologous lipopeptides: the lipid moiety consists of 3-amino-12methyltridecanoic or 3-amino-12-methyltetradecanoic acid; the peptide moiety contains one residue of each of the following seven amino acids: D-asparagine, L-aspartate, L-glutamate, L-proline, D-serine, L-threonine and D-tyrosine (Peypoux et al. 1981). Bacillomycin D (14) has also been isolated from an endophytic B. vallismortis ZZ185 which exhibited strong inhibition of the growth of several phytopathogenic fungi, including Fusarium graminearum, Alternaria alternata, Phytophthora capsici and Rhizoctonia solani (Zhenzhen et al. 2010).

Bacillomycin $\mathrm{F}$ is a cyclic peptidolipid isolated from B. subtilis. Preliminary studies have shown that bacillomycin $F$ belongs to the iturin group 


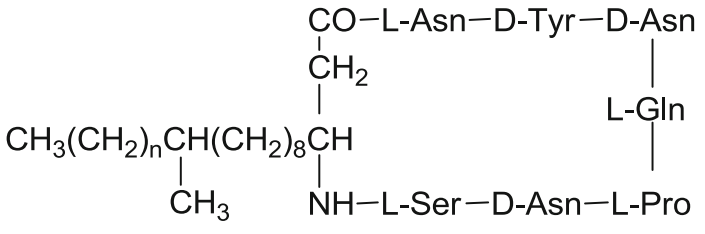

$\mathrm{n}=0$ or 1

13

$15 \mathrm{R}=\left(\mathrm{CH}_{2}\right)_{10} \mathrm{CH}_{3}$ $16 \mathrm{R}=\left(\mathrm{CH}_{2}\right)_{9} \mathrm{CH}\left(\mathrm{CH}_{3}\right) \mathrm{CH}_{3}$ $17 \mathrm{R}=\left(\mathrm{CH}_{2}\right)_{10} \mathrm{CH}\left(\mathrm{CH}_{3}\right) \mathrm{CH}_{3}$

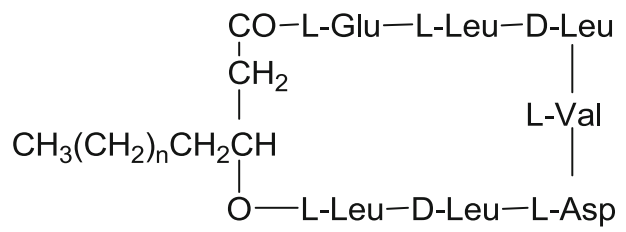

$\mathrm{n}=8,9$ or 10

19

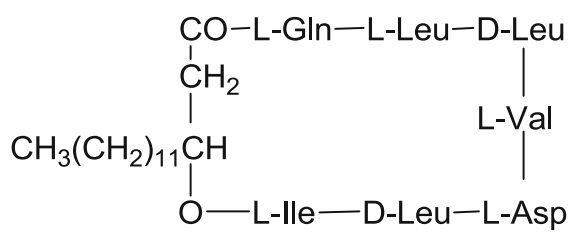

21

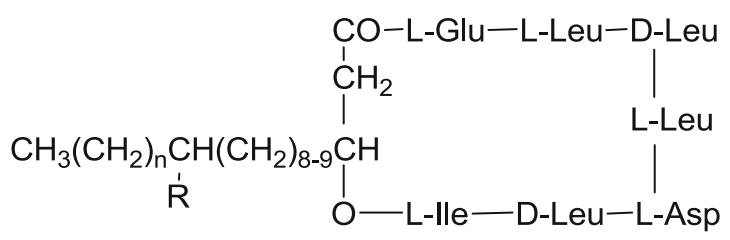

$\mathrm{n}=0$ or 1

$\mathrm{R}=\mathrm{H}$ or $\mathrm{CH}_{3}$

23

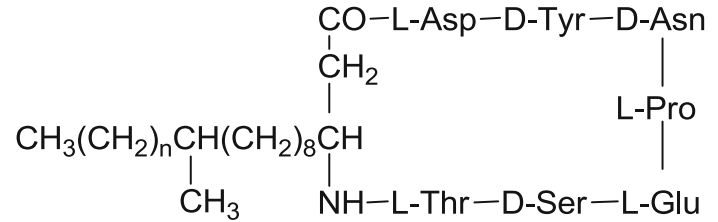
$\mathrm{n}=0$ or 1

14

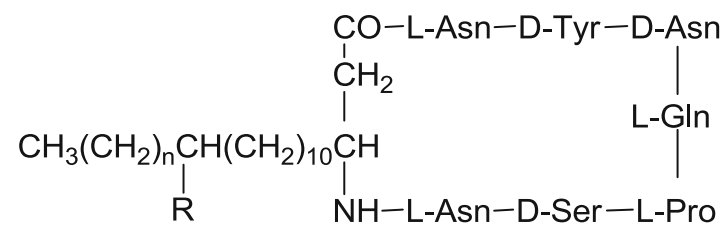

$\mathrm{n}=0$ or 1

$\mathrm{R}=\mathrm{H}$ or $\mathrm{CH}_{3}$

18

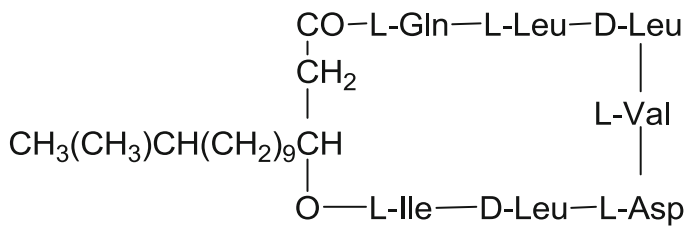

20

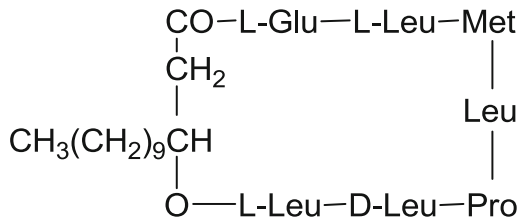

22

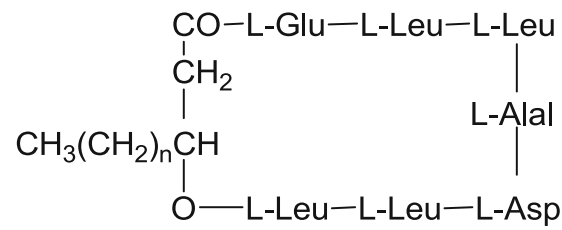

$24 n=12$

$25 n=13$

$26 n=14$

Fig. 4 Heptapeptides 
(Mhammedi et al. 1982), containing a peptide moiety with $\mathrm{L}$ and $\mathrm{D} \alpha$-amino acids and a lipid moiety principally consisting of a mixture of $\mathrm{C}_{16}$ and $\mathrm{C}_{17}$ $\beta$-amino acids. This antibiotic is related to iturin $\mathrm{A}$ (13) and possesses the same sequence except for the presence of an L-threonine instead of an L-serine residue which is linked to the $\beta$-amino acid (Peypoux et al. 1985).

Bacillomycin $\mathrm{L}$ is an antifungal agent isolated from a strain of B. subtilis. The peptide moiety contains D-aspartic acid, L-aspartic acid, L-glutamine, L-serine, D-serine, L-threonine, and D-tyrosine. The lipid moiety is a mixture of 3-amino-12-methyltridecanoic acid (46\%), 3-amino-12-methyltetradecanoic acid (38\%), 3-amino-14-methylpentadecanoic acid (11\%) and 2 minor homologs (Besson et al. 1977). This antibiotic lipopeptide belongs to the iturinic family of antifungal agents and acts with a strict sterol-phospholipid dependence on biomembranes (Volpon et al. 1999).

Bacillomycin Lc, a new antifungal antibiotic of the iturin class, was isolated from a strain of B. subtilis as a set of five congeners. The structure has been shown to differ from that of bacillomycin $\mathrm{L}$ by sequence changes from aspartate- 1 to asparagine- 1 and from glutamine- 5 to glutamate- 5 . The five congeners differ from one other only in the structure of the aliphatic side chain of the constituent $\beta$-amino acid (Eshita et al. 1995).

Bacillopeptins A (15), B (16), and C (17) (Fig. 4) were identified as iturin-group antifungal antibiotics, isolated from B. subtilis FR-2 (Kajimura et al. 1995). Their structures were elucidated as cyclic lipopeptides analogous to bacillomycin L, containing long-chain $\beta$-amino acids and L-Asn and L-Glu instead of the L-Asp and L-Gln residues found in bacillomycin L. Bacillopeptin C (17) proved active against yeasts and fungi, whereas bacillopeptins A (15) and B (16) did not exhibit any activity at $100 \mu \mathrm{g} / \mathrm{mL}$.

Mycosubtilin (18), isolated from B. subtilis, is a cyclopeptide consisting of seven $\alpha$-amino acids closed by a $\beta$-amino acid linkage similar to that found in other antibiotics of the iturin group (Peypoux et al. 1986). This compound has a strong lytic action on erythrocytes (Besson et al. 1989). Mycosubtilins B and C were isolated from $B$. subtilis and differ by the presence of a carboxyl group and carboxymethyl group respectively instead of a carboxamide group in previously described mycosubtilin (18) (Besson and Michel 1990).

\section{Surfactin family}

Surfactins, powerful amphiphilic membrane-active biosurfactant lipoheptapeptides with a structure similar to that of iturins, are not fungitoxic by themselves but do have some synergistic effects on the antifungal activity of iturin A (13) (Maget-Dana et al. 1992). Surfactin (19), produced by Bacillus species like $B$. subtilis (Rahman et al. 2006), B. amyloliquefaciens (Sun et al. 2006), B. licheniformis (Tendulkar et al. 2007), and B. natto (Kameda et al. 1974), is a heptapeptide with an LLDLLDL chiral sequence linked by a $\beta$-hydroxy fatty acid consisting of $13-15$ carbon atoms to form a cyclic lactone structure (Fig. 4) (Chen et al. 2009c).

The antagonistic lipopeptide surfactin (19), secreted by B. licheniformis BC98, had significant activity against different phytopathogenic fungi including Magnoporthe grisea (Tendulkar et al. 2007).

Surfactin (19) possessed antimicrobial (Vater 1986), antiviral (Kracht et al. 1999; Vollenbroich et al. 1997a), antitumor (Kameda et al. 1974), hemolytic (Kikuchi and Hasumi 2002), blood anticoagulant and fibrinolytic (Kim et al. 2006) activities. As one of the strongest biosurfactants (Nicolas 2003), surfactin (19) has numerous environmental and biotechnological applications (Solaiman 2005) and has proven to be particularly useful in oil recovery (Youssef et al. 2007), remediation of soil contaminated by heavy metals (Mulligan 2005) and biocontrol against phytopathogens (Bais et al. 2004) and insects (Assie et al. 2002). Diverse new properties have been identified including emulsification, foaming (Razafindralambo et al. 1998) inhibition of star-fish oocyte maturation (Toraya et al. 1995) and antimycoplasmic activities (Vollenbroich et al. 1997b).

The biological role of surfactin (19) is believed to support the colonization of surfaces and acquisition of nutrients through their surface-wetting and detergent properties. Surfactin (19) synthesized by B. amyloliquefaciens FZB42 protects it against bacteria and enables it to form biofilms thus equipping bacterium with powerful antagonistic advantages during surface colonization (Chen et al. 2009a).

The production of the lipopeptide biosurfactants lichenysins by various strains of $B$. licheniformis has been reported during the past few years (Jenny et al. 1993). Interest in such compounds has increased because of their successful applications for in situ microbial oil recovery and dispersion of oil spills 
(Clark et al. 1981). Elucidation of their structures has shown that the basal structure is similar to that of surfactin (19), the basic difference between surfactin (19) and lichenysin turning out to be an amide residue at position 1 (Gln) or 5 (Asn) in lichenysin instead of an acidic one in the case of surfactin (Grangemard et al. 1999).

Eight types of lichenysin commonly produced by $B$. licheniformis are lichenysin A (20), lichenysin B, lichenysin $\mathrm{C}$, lichenysin D, lichenysin G, [Val7] lichenysin G, [Ile4] lichenysin G and [Ile2,4] lichenysin G (Yakimov et al. 1995; Konz et al. 1999; Danders et al. 1982). Differences in lichenysin types are due to the kinds and sequences of amino acids in the lactone ring ( $\mathrm{Li}$ et al. 2008).

Lichenysin A (20) is a cyclic halotolerant lipoheptapeptide (Yakimov et al. 1997) produced by several B. licheniformis strains (Yakimov et al. 1995; Grangemard et al. 2001; Yakimov et al. 1999). The antibiotic activity of lichenysins was shown to be lower than that of surfactin (19) (Yakimov et al. 1995) but they are more potent surfactants than surfactins, thus emphasizing the predominant role of the carboxyl group in the aggregation process (Grangemard et al. 1999). Lichenysins are also produced by other Bacillus species such as a soil microorganism identified as B. megaterium (Pueyo et al. 2009).

Halobacillin (21) is an acylpeptide similar to surfactin (19) and is produced by a Bacillus species; culture CND-914, isolated from a deep-sea sediment core. Halobacillin (21) exhibited moderate human cancer cell cytotoxicity but, in contrast to the iturins, no antifungal or antibiotic activity (Trischman et al. 1994).

A complex of metabolites consisting of two isomeric cyclic acylpeptides identified as isomers of halobacillin (21) was isolated from a culture of Bacillus sp. A1238. The complex was designated isohalobacillin. Each molecule of isohalobacillin subcomponents contains either a 3-hydroxy-1-oxo13-methyltetradecyl or a 3-hydroxy-1-oxo-12-methyltetradecyl moiety instead of the 3-hydroxy-1-oxopentadecyl moiety found in the halobacillin (21). It inhibited Acyl-CoA: cholesterol acyltransferase activity: cholesterol acyltransferase, a microsomal enzyme that catalyzes the synthesis of cholesteryl esters from acyl-CoA and cholesterol, plays key roles in both intestinal absorption of cholesterol and cholesteryl ester accumulation in macrophages (Hasumi et al. 1995).
Bamylocin A (22), a novel lipopeptide related to surfactin (19) from B. amyloliquefaciens LP03 having antagonistic and crude oil-emulsifying activity, was isolated recently. As constituents of the peptide and lipophilic part, seven amino acids and $\beta$-hydroxy-C13 fatty acid were determined (Lee et al. 2007).

Other cyclic lipopeptides related to surfactin (19) are pumilacidins A (23), B, C, D, E, F and G, which were isolated from the culture broth of a strain of $B$. pumilus. They are cyclic acylheptapeptides composed of a $\beta$-hydroxy fatty acid, two L-leucine, two D-leucine, L-glutamic acid, L-aspartic acid and Lisoleucine (or L-valine). Pumilacidins A (23), $\mathrm{C}$ and $\mathrm{E}$ contain L-isoleucine at the $\mathrm{C}$-terminal, while pumilacidins $\mathrm{B}, \mathrm{D}, \mathrm{F}$ and $\mathrm{G}$ have $\mathrm{L}$-valine at this position. Pumilacidin screened as antiviral antibiotic active against herpes simplex virus was found to have inhibitory activity against gastric $\mathrm{H}^{+}, \mathrm{K}^{+}$-ATPase and to be protective against gastric ulcers in vivo (Naruse et al. 1990). A strong inhibitory activity against the fungi $R$. solani, Pythium aphanidermatum and Sclerotium rolfsii was exhibited by pumilacidin isolated from the cassava endophyte $B$. pumilus MAIIIM4a in Brazil (Pereira de Melo et al. 2009).

The implication of pumilacidin was also reported in food poisoning from a B. pumilus strain. The ability of pumilacidin to inactivate oxidative phosphorylation in mitochondria due to destruction of the cell membrane was suggested to explain some of the symptoms (From et al. 2007).

Three new lipopeptides (24-26), members of the surfactins family, were recently isolated from $B$. amyloliquefaciens BO7 (Fig. 4). These newly characterized lipopeptides exhibited a strong inhibitory activity against Fusarium oxysporum, an economically important fungal pathogen affecting a large number of different crop plants, highlighting their potential role in biocontrol activity of B. amyloliquefaciens (Romano et al. 2011).

\section{Hexapeptides}

Fusaricidins A (27), B, C and D, antifungal antibiotics more potent than bacillopeptins, were found to be produced by $B$. polymyxa KT-8 (Kajimura and Kaneda 1997). They are cyclic hexadepsipeptides all containing 15-guanidino-3-hydroxypentadecanoic acid as a side chain (Fig. 5). Fusaricidins strongly inhibit the growth of various kinds of fungi and show strong inhibitory activity against Gram-positive bacteria (Kaneda and Kajimura 2002). 


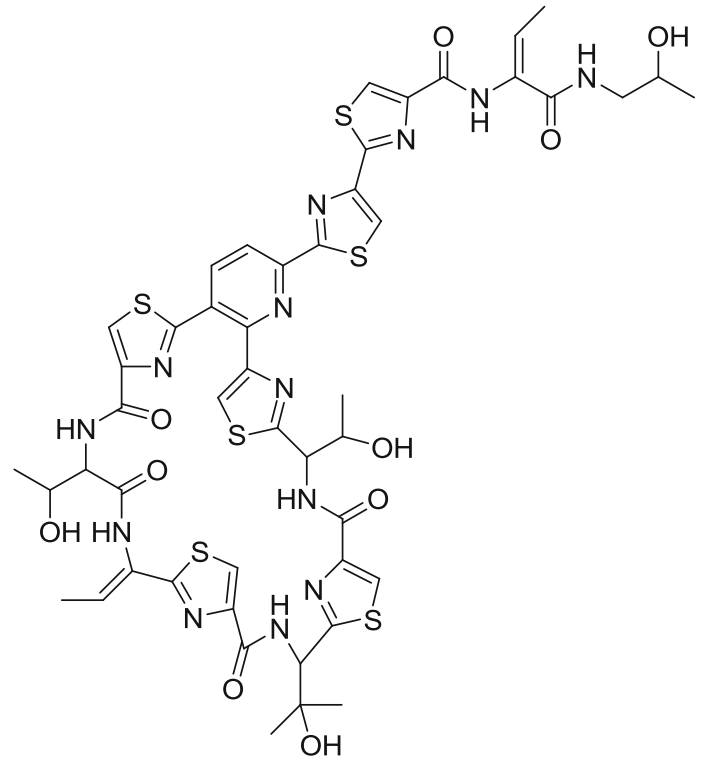

28

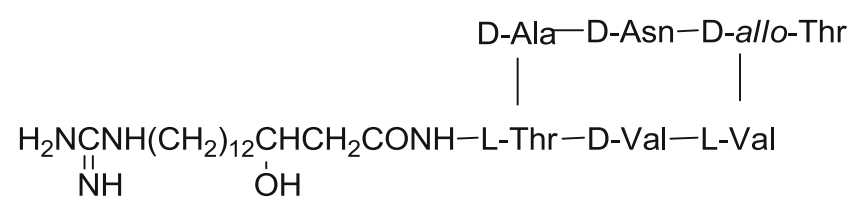

27

Fig. 5 Hexapeptides

A group of antibiotics characterized by high sulfur content were found to be produced by a variety of Bacillus species. Thiocillins I (28) and II were isolated from $B$. cereus G-15 and thiocillins II and III from $B$. badius AR-91. Also, the former two were probably produced by $B$. megatherium I-13. Thiocillins I (28), II and III show antimicrobial activity against Grampositive bacteria in vitro but not against Gramnegative bacteria (Shoji et al. 1976c). The differences between these antibiotics were clarified in their structural units (Shoji et al. 1981).

\section{Linear peptides}

Gramicidins A, B, and C are linear pentadecapeptides isolated from the soil bacterium A. migulanus (formerly known as $B$. brevis) together with the backbonecyclized cationic decapeptides gramicidin S (9) and tyrocidins (Mogi and Kita 2009).

In contrast to gramicidin $S$ (9) (Fig. 2), the structure of linear gramicidins like gramicidin $\mathrm{A}$ is an unconventional $\beta$-helix (6.3 amino acid residues per turn) with the alternating L- and D-amino acid composition except for position 2 (Gly) (Wallace 1986). All side chains point outward and linear gramicidins form $\mathrm{N}$-to-N termini dimeric ion channels (Wallace 1998) which selectively transport alkaline metal cations and protons across the lipid bilayer (Kelkar and Chattopadhyay 2007).

Five analogues of gramicidin A are also available from the bacterial extracts. Whereas gramicidin B differs from gramicidin A by a single Trp11 $\rightarrow$ Phe substitution, gramicidin $\mathrm{C}$ exhibits a Trp1 $\rightarrow$ Tyr replacement. In addition, a Val1 $\rightarrow$ Ile modification exists for each of these analogues (Vogt et al. 2003). Another analogue, gramicidin K, contains formyl and ethanolamine blocking groups and can be resolved into two components, one of which contains tyrosine. In lipid bilayer membranes, both components form channels of considerably longer lifetime and somewhat lower conductance than gramicidin A. Gramicidin K appears to be a lipopeptide that consists of a fatty acyl chain attached to the ethanolamine of gramicidin A (Koeppe et al. 1985).

Four compounds belonging to the class of lower mass lipopeptides were isolated from $B$. thuringiensis kurstaki $\mathrm{HD}-1$. The four kurstakins were found to have the same amino acid sequence, Thr-Gly-Ala-Ser-HisGln-Gln, but different fatty acids. Each lipopeptide has a lactone linkage between the carboxyl terminal amino acid and the hydroxyl group in the side chain of the serine residue. Their antifungal activity was demonstrated against Stachybotrys charatum (Hathout et al. 2000). 
Cerexins is a family of antibiotic peptides produced by B. cereus. Cerexins A (29) (Fig. 6) and $\mathrm{C}$ have been reported to be single entities whereas cerexins B and D are complexes of four acylpeptides whose only difference is a fatty acyl residue (Shoji et al. 1979).

The constituent fatty acid of cerexin A (29), an antibiotic active against Gram-positive bacteria, was elucidated to be $\beta$-hydroxy isoundecanoic acid. The asparaginyl asparagine linkage in the amino acid sequence of the antibiotic proved to be a normal $\alpha$-carboxyl peptide bond (Shoji et al. 1976d).

Cerexin B is another amphoteric antibiotic produced by B. cereus, closely related to cerexin A (29). The essential difference between them was shown to be the replacement of serine and one valine residue in cerexin A (29) by glycine and phenylalanine in cerexin B (Shoji and Hinoo 1975). The constituent fatty acids for cerexin $B$ were elucidated to be $\beta$-hydroxy isodecanoic acid, $\beta$-hydroxy decanoic acid, $\beta$-hydroxy isoundecanoic acid and $\beta$-hydroxy anteisoundecanoic acid (Shoji and Kato 1976b).
Cerexins $\mathrm{C}$ and $\mathrm{D}$ are closely related to cerexins $\mathrm{A}$ (29) and B in their physical-chemical and antimicrobial properties. While active against Gram-positive bacteria, they are somewhat less active than cerexin A (29). The fatty acid constituents of cerexins A (29) and $\mathrm{C}$ and cerexins $\mathrm{B}$ and $\mathrm{D}$ are essentially the same. It was concluded that cerexins $\mathrm{C}$ and $\mathrm{D}$ are the acylpeptides analogous to cerexins A (29) and B, respectively, in which the $\gamma$-hydroxylysine residue is replaced by a lysine residue (Shoji et al. 1976e).

The tridecaptin group of antibiotics produced by strains of B. polymyxa contains tridecaptins A (30), B and $\mathrm{C}$ differing from one other in their fatty acid components and amino acid residues (Fig. 6) (Kato et al. 1978). Tridecaptins are assumed to be linear acyl tridecapeptides active against Gram-negative and Gram-positive bacteria in vitro and in vivo (Kato et al. 1979). Each one of the three tridecaptins has been reported to be a complex (Shoji et al. 1979).

Edeines is a mixture of closely related basic peptide antibiotics produced by the B. brevis $\mathrm{Vm} 4$ strain. These compounds are linear pentapeptide amides with
Fig. 6 Linear peptides isolated from Bacillus genus

$$
\begin{gathered}
\beta \text {-hydroxy isoundecanoyl-D-Asn-D-Val-D-Val-L-Asn-D-Asn-L- } \gamma-H y l-D-\alpha-T h r-L-S e r-D-T r p-D-\alpha-\| l \\
\text { L- } \gamma-H y l=L-t h r e o-\gamma-h y d r o x y l y s i n e
\end{gathered}
$$$$
29
$$

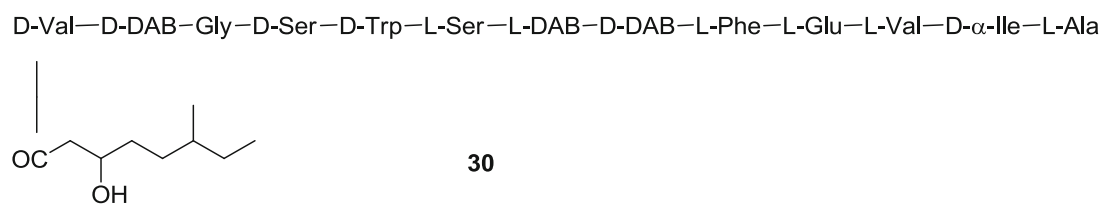<smiles>NCCCCNCCCNC(=O)CNC(=O)C[C@@H](O)[C@H](N)CCC[C@@H](NC(=O)[C@H](CN)NC(=O)[C@H](O)CNC(=O)C[C@H](N)c1ccc(O)cc1)C(=O)O</smiles>

31

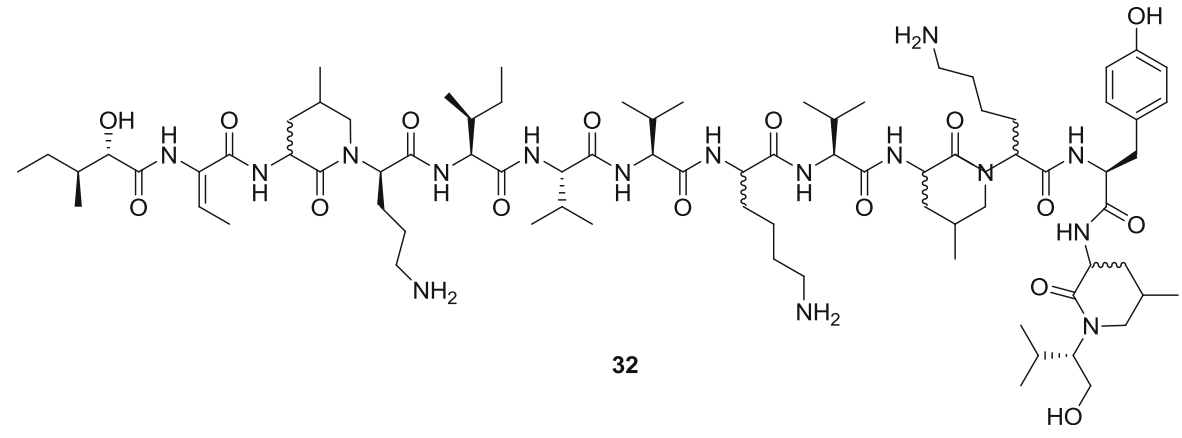


an unusual amino acid composition; in addition to glycine, the molecule consists of isoserine, $\beta$-tyrosine, $\alpha, \beta$-diaminopropionic acid, and 2,6-diamino-7-hydroxyazaleic acid. The glycine residue in edeine A (31) is attached to the basic constituent, spermidine. In the case of edeine $\mathrm{B}$, the base is guanylspermidine ( $N$-guanyl- $N^{\prime}$-(3-aminopropyl)-1,4-diaminobutane). The structure of edeine $\mathrm{D}$ is similar to edeine A (31) with $\beta$-phenyl- $\beta$-alanine substituting for $\beta$-tyrosine. Edeine $\mathrm{F}$ is composed of amino acids: $(S)-\beta$-phenyl- $\beta$ alanine, $(S)$-isoserine, $(S)$-2,3-diaminopropionic acid, $(2 R, 6 S)$-diamino-(7R)-hydroxyazaleic acid, glycine and a polyamine guanidylspermidine (Fig. 6) (Wojciechowska et al. 1983). It was shown that the free ionizable carboxy group in the $(2 R, 6 S, 7 R)$-2,6-diamino-7-hydroxyazaleic acid moiety is not essential for biological activity in these compounds (Czajgucki et al. 2006).

Edeines exhibit a broad spectrum of antimicrobial activity including Gram-positive and Gram-negative bacteria, yeasts, mould (Chmara and Borowski 1968), and mycoplasmas (Borysiewicz 1966), but their high animal toxicity does not permit their application in chemotherapy as antimicrobial agents. These peptides have the ability to eliminate plasmids determining antibiotic resistance from bacterial cells (Borowski et al. 1977a) and they demonstrate considerable immunosuppressive effects in mice (Borowski et al. 1977b). Edeine antibiotics specifically and reversibly inhibit the biosynthesis of DNA (Kuryło-Borowska and Szer 1972) and have the ability to differentiate prokaryotic and eukaryotic microorganisms based on differences in functioning and structure of the DNA replicating systems (Woynarowska et al. 1979). Edeines are also universal inhibitors of protein synthesis (Obrig et al. 1971).

The strain B. licheniformis M-4 produces a hydrophilic peptide with antifungal activity named fungicin M4. It contains the amino acids Glu (8), Arg (5), Pro (4), Tyr (8), Val (3), Met (2) and Orn (4). Its inhibitory spectrum is limited to Microsporum canis CECT 2797, Mucor mucedo CECT 2653, Mucor plumbeus CCM F 443, Sporothrix schenckii CECT 2799, B. megaterium and Corynebacterium glutamicum CECT 78 (Lebbadi et al. 1994).

Bogorol cationic peptide antibiotics contain a number of unusual structural features which include the reduction of the C-terminal residue to valinol, an $\mathrm{N}$-terminal residue of 2-hydroxy-3-methylpentanoic acid, the incorporation of four D-amino acids and the presence of a dehydroamino acid. Bogorols show selective and relatively potent activity against methicillin-resistant $S$. aureus and vancomycin-resistant Enterococcus spp., as well as moderate activity against E. coli (Barsby et al. 2006). The most representative compound of this family, bogorol A (32), isolated from a strain of B. laterosporus obtained from a marine habitat, was shown to have antimicrobial activity against several human pathogens including S. aureus, E. coli, Enterococcus faecalis, Stenotrophomonas maltophilia, Burkholderia cepacia and C. albicans (Andersen et al. 2002; Barsby et al. 2001).

Esperin is an antibiotic isolated from a strain of $B$. mesentericus (Ogawa and Ito 1951). Esperin contains the sequence $\mathrm{R}-\mathrm{CH}(\mathrm{OH}) \mathrm{CH}_{2} \mathrm{CO}-\mathrm{Glu}-\mathrm{Leu}-\mathrm{Leu}-\mathrm{Val}-$ Asp-Leu-Leu(Val) where $\mathrm{R}$ is a mixture of $\mathrm{C}_{10} \mathrm{H}_{21}$, $\mathrm{C}_{11} \mathrm{H}_{23}$, and $\mathrm{C}_{12} \mathrm{H}_{25}$, and the $\mathrm{C}$-terminal residue contains a $30 \%$ replacement by valine, with a lactone formed by the $\mathrm{OH}$ group of the fatty acid constituent and the carboxylic acid function of the aspartic acid residue (Thomas and Ito 1969).

Laterosporin A and laterosporin B are two very similar antibiotics produced by B. laterosporus which were active against Corynebacterium xerosis, $S$. aureus and Mycobacterium phlei (Barnes 1949).

\section{Di- and tripeptides}

Two acyldipeptides, tupuseleiamides A (33) and B (34) (Fig. 7), in which the amino acids both have the nonprotein D configuration, are produced by a $B$. laterosporus isolate obtained from a tropical marine habitat. Studies on tupuseleiamide A (33) revealed the presence of D-tyrosine and D-serine with a 7-methyloctanoyl fragment which accounted for the remaining site of unsaturation. Analysis for tupuseleiamide B (34) showed that it differed from tupuseleiamide A (33) only in the methyloctanoyl fragment (Barsby et al. 2002).

Bacilysin (35), also named tetaine (Kaminski and Sokolowska 1973), is a dipeptide antibiotic containing an epoxyaminoacid moiety, and L-alanine residue at the $\mathrm{N}$-terminus and a non-proteinogenic amino acid, L-anticapsin, at the C-terminus (Rogers et al. 1965). Bacilysin (35), produced by B. subtilis (Loeffler et al. 1986; Abraham 1965; Newton 1949), B. pumilus (Chmara and Borowski, 1973; Steinborn et al. 2005) 
Fig. 7 Di- and Tripeptides<smiles>[R]C(C)C([R])CCCCC(=O)N[C@@H](CO)C(=O)N[C@@H](Cc1ccc(O)cc1)C(=O)O</smiles><smiles>CC(N)C(=O)NC(C)C(=O)O</smiles>
$33 \mathrm{R}_{1}=\mathrm{H} ; \mathrm{R}_{2}=\mathrm{CH}_{3}$<smiles>N=C(N)NCCC[C@H](N)C(=O)NC(/C=C\CP(=O)([O-])[O-])C(=O)[O-]</smiles>

and B. amyloliquefaciens (Chen et al. 2009b), is active against a wide range of bacteria like $S$. aureus, Corynebacterium xerose and E. coli and against yeast C. albicans due to the anticapsin moiety which is released after uptake into susceptible cells (Chmara et al. 1980).

Bacilipins A and B, unsaturated aliphatic N-containing acids related to bacilysin (35), produced by $B$. subtilis A14, are active against $M$. phlei. The action of these antibiotics was enhanced when used as mixture (Newton 1949).

Chlorotetaine is a natural product isolated from the B. subtilis strain BGSC1E2 (Rapp et al. 1988a) and B. amyloliquefaciens (Argüelles-Arias et al. 2009). It is related to the longer known dipeptide bacilysin (35) containing the new amino acid $(R)-3^{\prime}$-chloro- $4^{\prime}$-oxo$2^{\prime}$-hexenylalanine (Fig. 7). Chlorotetaine inhibited various fungi and, at higher concentrations, Grampositive and Gram-negative bacteria. It is the first $\mathrm{Cl}$ containing dipeptide identified as a metabolite of $B$. subtilis (Rapp et al. 1988a).

Rhizocticins are phosphonate-containing oligopeptide antibiotics produced by the Gram-positive bacterium B. subtilis ATCC6633 (Michener and Snell 1949; Rapp et al. 1988b). They are di- and tripeptide antibiotics consisting of a variable amino acid at the $\mathrm{N}$ terminus followed by arginine and the nonproteinogenic amino acid (Z)-L-2-amino-5-phosphono-3-pentenoic acid (APPA) (Borisova et al. 2010). Rhizocticins consist of four antifungal hydrophilic peptide antibiotics: L-arginyl-L-2-amino-5-phosphono-3-cis-pentenoic acid (rhizocticin A (36)), L-valyl-L-arginyl-L-2-amino-5phosphono-3-cis-pentenoic acid (rhizocticin B); and rhizocticin $C$ and $D$ which are the same as rhizocticin but contain L-Ile and L-Leu, respectively, in place of L-Val (Fig. 7) (Kino et al. 2009). Filamentous fungi as well as the cultivated nematode Caenorhabditis elegans were found to be sensitive to rhizocticin A (36), while bacteria and the protozoan Paramecium caudatum were not (Kugler et al. 1990).

\section{Siderophores}

Many organisms produce highly specific chelators called siderophores in response to iron limitation. These siderophores chelate and transport iron via specific transport systems to promote cell growth and primarily utilize either hydroxamic acids or catechols for the chelating ligands. Most of the hydroxamatecontaining siderophores, including ferrichrome, aerobactin, and mycobactins, contain $\omega$ - $N$-hydroxy L-amino acids. However, others such as schizokinen (37) (Fig. 8) and ferrioxamine B, utilize 1-amino- $\omega$ (hydroxyamino) alkane residues to bind ferric ion (Lee and Miller 1983).

A specific siderophore is often synthesized by more than one species of microbes. B. subtilis utilized 3 types of hydroxamate siderophores, ferrichromes (Takimura et al. 2004), ferrioxamines (Ollinger et al. 2006) and shizokinen (37), each of which is taken up by different transport systems (Schneider and Hantke 1993). 
Fig. 8 Siderophores isolated from Bacillus genus<smiles>CC(=O)N(O)CCCNC(=O)CC(O)(CC(=O)NCCCN(O)C(C)=O)C(=O)O</smiles>

37<smiles>C[C@H](OC(=O)[C@H](NC(=O)CNC(=O)c1cccc(O)c1O)[C@@H](C)OC(=O)[C@H](NC(=O)CNC(=O)c1cccc(O)c1O)[C@@H](C)OC(=O)[C@H](NC(=O)CNC(=O)c1cccc(O)c1O)C(=O)O)[C@@H](C)NC(=O)CNC(=O)c1cccc(O)c1O</smiles>

38<smiles>O=C(CC(O)(CC(=O)NCCCNCCCCNC(=O)c1ccc(O)c(O)c1)C(=O)O)NCCCCNCCCNC(=O)c1ccc(O)c(O)c1</smiles>

Bacillus megaterium ATCC 19213 produces the dihydroxamate siderophore schizokinen (37). This compound was originally isolated as a factor active in the initiation of cell division (Lankford et al. 1966; Byers et al. 1967) and later shown to be important in iron uptake (Mullis et al. 1971). Schizokinen (37) consists of two residues of L-amino-3-( $\mathrm{N}$-acetylhydroxyamino) propane linked to the two terminal carboxyl groups of a citric acid residue by amide bonds (Fig. 8). The two hydroxamate groups and the hydroxyl and carboxyl groups on the citrate backbone form the six coordination sites for ferric iron (Plowman et al. 1984).

The monohydroxamate siderophore $N$-deoxyschizokinen was isolated from B. megaterium ATCC 19213 and identified as 4-[(3-(acetylhydroxyamino) propyl) amino]-2-[2-[(3-(acetylamino) propyl) amino]-2-oxoethyl]-2-hydroxy-4-oxo-butanoic acid. It has the same carbon skeleton as schizokinen (37) but the hydroxyl group on one hydroxamate is replaced by hydrogen (Hu and Boyer 1995).

In addition to their high affinity for ferric ions, these siderophores, schizokinen (37) and N-deoxyschizokinen, chelate aluminum. Aluminum was absorbed by $B$. megaterium ATCC 19213 through the siderophore transport receptor providing an extra pathway for aluminum accumulation into iron-deficient aluminum accumulation (Hu and Boyer 1996).

The classical catecholate siderophores contain 2,3dihydroxybenzoic acid (2,3-DHB) at the iron binding center of the molecule and siderophores based on this moiety have been found in many bacterial species. These microorganisms use orthologs of a common four-gene operon for synthesis of 2,3-DHB from the bacterial aromatic biosynthetic pathway. Thus, the siderophore of B. licheniformis K11 (siderophore K11) was determined to be a catechol type siderophore which is produced generally by Bacillus spp. (Woo et al. 2007).

The first example of a bacterial catecholate siderophore to be structurally characterized was itoic acid (2,3-dihydroxybenzoylglycine) isolated from low iron fermentation cultures of B. subtilis (Ito 1993).

Bacillibactin (38), a catecholic trilactone (2,3dihydroxybenzoate-glycinethreonine) (Fig. 8) (Miethke et al. 2006), is a hexadentate siderophore produced by $B$. subtilis (Raza et al. 2008), $B$. anthracis, B. cereus, B. thuringiensis (Wilson et al. 2006), B. amyloliquefaciens (Chen et al. 2009b) and $B$. licheniformis (Temirov et al. 2003). Bacillibactin (38) and many of the siderophores are synthesized nonribosomally by large, multidomain enzymes termed as 
nonribosomal peptide synthetases (NRPS) that can assemble peptides of wide structural diversity and broad biological activity (Konz and Marahiel 1999). Bacillibactin (38) binds iron through three 2,3-catecholamide moieties linked to a trithreonine scaffold via glycine spacers (Abergel et al. 2009).

The majority of all catecholate siderophores which have been structurally characterized are 2,3-dihydroxybenzoate-containing species. In fact, only petrobactin (39) and a related siderophore, petrobactin sulfate, have been reported to contain the 3,4-dihydroxyl substitution pattern (Garner et al. 2004).

The hexadentate 3,4-catecholate/citrate siderophore petrobactin (39) is produced by the mammalian pathogens B. anthracis (Koppisch et al. 2005) and $B$. cereus (Wilson et al. 2006), apparently to evade the immune protein siderocalin and mediate their iron acquisition during infection; it is essential for the pathogenicity of these organisms.

Bacillus anthracis, the causative agent of anthrax, is a Gram-positive, spore-forming bacterium that readily infects a variety of mammals. Targeted inhibition of the biosynthesis of the essential siderophore petrobactin (39), may hold promise as a potential therapeutic treatment against anthrax. Several studies have focused on characterizing the enzymes responsible for petrobactin (39) biosynthesis and designing inhibitors for key biosynthetic steps (Pfleger et al. 2009).

\section{Concluding remarks}

Bacilli have been known for their biosynthetic potential in the production of ribosomal and nonribosomal bioactive natural products. In recent years, great efforts have been made to elucidate the molecular structures of an important number of bioactive nonribosomal peptides isolated from Bacillus species in order to discover the enzymatic mechanisms involved in biosynthesis and to decipher the role played by the genes involved and their regulation. While knowledge is already available on the production and characterization of a vast number of nonribosomal peptides by bacilli, as indicated in this review an important number of peptides structures remain uncharacterized and a great deal of confusing data about peptides abound in the literature.

Genomics has transformed the way in which we think about these microorganisms and has greatly influenced the manner in which we probe their chemistry and biology. A large number of complete and draft genome sequences are now available and Bacillus is probably one of the best characterised chemically and one of the most frequently represented genera in the genomic databases bearing witness to the importance of this genus in environmental processes, industrial applications and medicine.

Hopefully, this information will contribute to a better understanding of the features that divide this family into pathogens and environmental and industrial isolates. Furthermore, the genomic data will contribute to a deeper understanding of ecological adaptations when correlating genes with pathogenic potential and with the production of bioactive peptides and metabolites in general, and will help to characterize the vast number of bioactive nonribosomal peptides whose structures remain unresolved.

Although a vast number of bioactive peptides from Bacillus genus have been reported, we now know that, in general, conventional natural product isolation programs vastly underestimated their biosynthetic ability, in many cases by upwards of 80-90 \% (Nett et al. 2009). As a consequence, orphan secondary metabolic gene clusters deduced from genome sequencing efforts represent an unexplored resource of new chemical entities that promise to provide a novel source of bioactive peptides. Hence, one of the greatest future challenges in this field will be to develop general methods to trigger these silent gene clusters and characterize the chemical biology of their pathway products (Williams et al. 2008).

Further investigation of new antibiotic peptides and their complex regulation of biosynthesis genes will continue to be a fruitful approach to developing a more complete understanding of the biology and metabolite production by these bacteria (Harwood and Cranenburgh 2008). Future sequencing efforts will stimulate the broader scientific community to search for new peptides and lead structures for industrial applications: biosurfactancts (Raaijmakers et al. 2010), plant bioprotectants (Romano et al. 2011), pharmaceutical and agrochemical development (Seydlova and Svobodova 2008), etc., and to exploit commercial strains optimized for the biocontrol of pathogens (in plants and animals) (Harwood and Cranenburgh 2008; Jourdan et al. 2009), in order to prevent the post-harvest loss of fruits and vegetables, such as probiotics (Hong et al. 2005) and for the production of other molecules of 
industrial interest such as enzymes (amylases or proteases) or native and heterologous proteins (Ongena and Jacques 2008).

Acknowledgments I.G.C. gratefully acknowledges to Prof. Dr. A. Galvez for the carefully reading of the manuscript and MEC for Grant AGL2012-39798-CO2-01.

\section{References}

Abergel RJ, Zawadzka AM, Hoette TM, Raymond KN (2009) Enzymatic hydrolysis of trilactone siderophores: where chiral recognition occurs in enterobactin and bacillibactin iron transport. J Am Chem Soc 131(35):12682-12692

Abraham GF (1965) Production and purification of bacilysin. Biochem J 97(2):573-578

Abriouel H, Franz CMAP, Ben Omar N, Gálvez A (2011) Diversity and applications of Bacillus bacteriocins. FEMS Microbiol Rev 35:201-232

Agata N, Mori M, Ohta M, Suwan S, Ohtani I, Isobe M (1994) A novel dodecadepsipeptide, cereulide, isolated from Bacillus cereus causes vacuole formation in HEp-2 cells. FEMS Microbiol Lett 121(1):31-34

Alcaraz LD, Olmedo G, Bonilla G, Cerritos R, Hernández G, Cruz A, Ramírez E, Putonti C, Jiménez B, Martínez E, López V, Arvizu JL, Ayala F, Razo F, Caballero J, Siefert J, Eguiarte L, Vielle J-P, Martínez O, Souza V, HerreraEstrella A, Herrera-Estrella L (2008) The genome of Bacillus coahuilensis reveals adaptations essential for survival in the relic of an ancient marine environment. Proc Natl Acad Sci USA 105:5803-5808

Alcaraz LD, Moreno-Hagelsieb G, Eguiarte LE, Souza V, Herrera-Estrella L, Olmedo G (2010) Understanding the evolutionary relationships and major traits of Bacillus through comparative genomics. BMC Genomics 11:332

Andersen RJ, Kelly MT, Barsby TA (2002) Peptide antibiotics. US Pat. US 2002035239 A1 20020321

Anderson I, Sorokin A, Kapatral V, Reznik G, Bhattacharya A, Mikhailova N, Burd H, Joukov V, Kaznadzey D, Walunas T, Souza M, Larsen N, Pusch G, Liolios K, Grechkin Y, Lapidus A, Goltsman E, Chu L, Fonstein M, Ehrlich SD, Overbeek R, Kyrpides N, Ivanova N (2005) Comparative genome analysis of Bacillus cereus group genomes with Bacillus subtilis. FEMS Microbiol Lett 250:175-184

Aranda FJ, Teruel JA, Ortiz A (2005) Further aspects on the hemolytic activity of the antibiotic lipopeptide iturin A. Biochim Biophys Acta Biomembr 1713(1):51-56

Argüelles-Arias A, Ongena M, Halimi B, Lara Y, Brans A, Joris B, Fickers P (2009) Bacillus amyloliquefaciens GA1 as a source of potent antibiotics and other secondary metabolites for biocontrol of plant pathogens. Microb Cell Fact 8:63

Arnesen LPS, Fagerlund A, Granum PE (2008) Fromsoil to gut: Bacillus cereus and its food poisoning toxins. FEMS Microbiol Rev 32:579-606

Arrebola E, Jacobs R, Korsten L (2010) Iturin A is the principal inhibitor in the biocontrol activity of Bacillus amyloliquefaciens PPCB004 against postharvest fungal pathogens. J Appl Microbiol 108(2):386-395
Assie LK, Deleu M, Arnaud L, Paquot M, Thonart P, Gaspar Ch, Haubruge E (2002) Insecticide activity of surfactins and iturins from a biopesticide Bacillus subtilis Cohn (S499 strain). Biol Wet 67(3):647-655

Bais HP, Fall R, Vivanco JM (2004) Biocontrol of Bacillus subtilis against infection of arabidopsis roots by Pseudomonas syringae is facilitated by biofilm formation and surfactin production. Plant Physiol 134:307-319

Barnes EM (1949) Laterosporin A and laterosporin B antibiotics produced by Bacillus laterosporus. $\mathrm{Br} \mathrm{J}$ Exp Pathol 30:100-104

Barsby T, Kelly MT, Gagne SM, Andersen RJ, Bogorol A (2001) Produced in culture by a marine Bacillus sp. reveals a novel template for cationic peptide antibiotics. Org Lett 3(3):437-440

Barsby T, Kelly MT, Andersen RJ (2002) Tupuseleiamides and basiliskamides, new acyldipeptides and antifungal polyketides produced in culture by a Bacillus laterosporus isolate obtained from a tropical marine habitat. J Nat Prod 65(10):1447-1451

Barsby T, Warabi K, Sorensen D, Zimmerman WT, Kelly MT, Andersen RJ (2006) The bogorol family of antibiotics: template-based structure elucidation and a new approach to positioning enantiomeric pairs of amino acids. J Org Chem 71(16):6031-6037

Besson F, Michel G (1987) Isolation and characterization of new iturins: iturin D and iturin E. J Antibiot 40(4):437-442

Besson F, Michel G (1990) Mycosubtilins B and C: minor antibiotics from mycosubtilin-producer Bacillus subtilis. Microbios 62(251):93-99

Besson F, Peypoux F, Michel G, Delcambe L (1976) Characterization of iturin A in antibiotics from various strains of Bacillus subtilis. J Antibiot 29(10):1043-1049

Besson F, Peypoux F, Michel G, Delcambe L (1977) The structure of bacillomycin L, an antibiotic from Bacillus subtilis. Eur J Biochem 77(1):61-67

Besson F, Quentin MJ, Michel G (1989) Action of mycosubtilin on erythrocytes and artificial membranes. Microbios 59(240-241):137-143

Bhattacharjya S, David SA, Mathan VI, Balaram P (1997) Polymyxin B nonapeptide: conformations in water and in the lipopolysaccharide-bound state determined by twodimensional NMR and molecular dynamics biopolymers. Biopolymers 41:251-265

Bode HB (2009) Entomopathogenic bacteria as a source of secondary metabolites. Curr Opin Chem Biol 13:224-230

Borisova SA, Circello BT, Zhang JK, van der Donk WA, Metcalf WW (2010) Biosynthesis of rhizocticins, antifungal phosphonate oligopeptides produced by Bacillus subtilis ATCC6633. Chem Biol 17(1):28-37

Borowski J, Borowski E, Ciepat A, Dzierzanowska D, Jakubicz P, Smorczewski A (1977a) Elimination of plasmids determining bacterial antibiotic resistance by edeine. Drugs Exp Clin Res 3:189-191

Borowski J, Jakoniuk P, Borowski E (1977b) Edeine as an immunosuppressive agent. Drugs Exp Clin Res 3:183-188

Borysiewicz J (1966) Effect of various inhibitors of protein and deoxyribonucleic acid synthesis on the growth of mycoplasmas. Appl Microbiol 14:1049-1050

Bozdogan B, Galopin S, Gerbaud G, Courvalin P, Leclercq R (2003) Chromosomal aadD2 encodes an aminoglycoside 
nucleotidyltransferase in Bacillus clausii. Antimicrob Agents Chemother 47:1343-1346

Brownlee G, Bushby SRM, Short EI (1949) Comparative biological studies of polymyxin A and D. Ann N Y Acad Sci 51:891-896

Byers BR, Powell MV, Lankford CE (1967) Iron-chelating hydroxamic acid (schizokinen) active in initiation of cell division in Bacillus megaterium. J Bacteriol 93(1):286-294

Calderone ChT, Kowtoniuk WE, Kelleher NL, Walsh ChT, Dorrestein PC (2006) Convergence of isoprene and polyketide biosynthetic machinery: isoprenyl-S-carrier proteins in the pksX pathway of Bacillus subtilis. Proc Natl Acad Sci USA 103(24):8977-8982

Cerritos R, Vinuesa P, Eguiarte LE, Herrera-Estrella L, AlcarazPeraza LD, Arvizu-Gómez JL, Olmedo G, Ramírez E, Siefert JL, Souza V (2008) Bacillus coahuilensis sp. nov., a moderately halophilic species from a desiccation lagoon in the Cuatro Ciénegas Valley in Coahuila, Mexico. Int J Syst Evol Microbiol 58:919-923

Challacombe JF, Altherr MR, Xie G, Bhotika SS, Brown N, Bruce D, Campbell CS, Campbell ML, Chen J, Chertkov O et al (2007) The complete genome sequence of Bacillus thuringiensis Al Hakam. J Bacteriol 189:3680-3681

Challis GL (2008) Mining microbial genomes for new natural products and biosynthetic pathways. Microbiology 154 : $1555-1569$

Charbonneau DL, Buchanan W, Donovan-Brand RJ (1998) Polymyxin A, B, C, D, or E containing compositions for the treatment of periodontal disease, plaque and breath malodor. Brit. UK Patent GB 2319726

Chen X-H, Koumoutsi A, Scholz R, Eisenreich A, Schneider K, Heinemeyer I, Morgenstern B, Voss B, Hess WR, Reva O, Junge H, Voigt B, Jungblut PR, Vater J, Suessmuth R, Liesegang H, Strittmatter A, Gottschalk G, Borriss R (2007) Comparative analysis of the complete genome sequence of the plant growth-promoting bacterium Bacillus amyloliquefaciens FZB42. Nat Biotechnol 25:1007-1014

Chen X-H, Koumoutsi A, Scholz R, Borriss R (2009a) More than anticipated-production of antibiotics and other secondary metabolites by Bacillus amyloliquefaciens. J Mol Microbiol Biotechnol 16:14-24

Chen X-H, Scholz R, Borriss M, Junge H, Moegel G, Kunz S, Borriss R (2009b) Difficidin and bacilysin produced by plant-associated Bacillus amyloliquefaciens are efficient in controlling fire blight disease. J Biotechnol 140:38-44

Chen X-H, Koumoutsi A, Scholz R, Schneider K, Vater J, Süssmuth R, Piel J, Borriss R (2009c) Genome analysis of Bacillus amyloliquefaciens FZB42 reveals its potential for biocontrol of plant pathogens. J Biotechnol 140:27-37

Chmara H, Borowski E (1968) Antibiotic edeine: VII. Biological activity of edeine A and B. Acta Microbiol Pol 17:59-66

Chmara H, Borowski E (1973) Antibiotic tetaine, a new inhibitor of murein precursor's synthesis in Escherichia coli K-12. Biochem Biophys Res Commun 52(4):1381-1387

Chmara H, Smulkowski M, Borowski E (1980) Growth inhibitory effect of amidotransferase inhibition in Candida albicans by epoxypeptides. Drugs Exp Clin Res 6:7-14

Clark JB, Munnecke DM, Jenneman GE (1981) In situ microbial enhancement of oil production. Dev Ind Microbiol 22:695-701
Czajgucki Z, Andruszkiewicz R, Kamysz W (2006) Structure activity relationship studies on the antimicrobial activity of novel edeine A and D analogues. J Pept Sci 12:653-662

Danders W, Marahiel MA, Krause M, Kosui N, Katom T, Izumiya N, Kleinkauf H (1982) Antibacterial action of gramicidin $\mathrm{S}$ and tyrocidines in relation to active transport, in vitro transcription, and spore outgrowth. Antimicrob Agents Chemother 22(5):785-790

Davidson B (1995) New dimensions in natural products research: cultured marine microorganisms. Curr Opin Biotechnol 6:284-291

Deleu M, Paquot M, Nylander T (2008) Effect of fengycin, a lipopeptide produced by Bacillus subtilis, on model biomembranes. Biophys J 94:2667-2679

Dommel MK, Lücking G, Scherer S, Ehling-Schulz M (2011) Transcriptional kinetic analyses of cereulide synthetase genes with respect to growth, sporulation and emetic toxin production in Bacillus cereus. Food Microbiol 28:284-290

Drobniewsk FA (1993) Bacillus cereus and related species. Clin Microbiol Rev 6:324-338

Ehling-Schulz M, Fricker M, Scherer S (2004) Bacillus cereus, the causative agent of an emetic type of food-borne illness. Mol Nutr Food Res 48:479-487

Ehling-Schulz M, Fricker M, Grallert H, Rieck P, Wagner M, Scherer S (2006) Cereulide synthetase gene cluster from emetic Bacillus cereus: structure and location on a mega virulence plasmid related to Bacillus anthracis toxin plasmid pXO1. BMC Microbiol 6:20

Erickson RJ (1976) Industrial applications of the bacilli: a review and prospectus. In: Schlesinger D (ed) Microbiology. ASM Press, Washington, DC, pp 406-419

Eshita SM, Roberto NH, Beale JM, Mamiya BM, Workman RF (1995) Bacillomycin Lc, a new antibiotic of the iturin group: isolations, structures, and antifungal activities of the congeners. J Antibiot 48(11):1240-1247

Finking R, Marahiel MA (2004) Biosynthesis of nonribosomal peptides. Annu Rev Microbiol 58:453-488

Fischbach MA, Walsh CT (2006) Assembly-line enzymology for polyketide and nonribosomal peptide antibiotics: logic, machinery, and mechanisms. Chem Rev 106:3468-3496 and references therein cited

Fravel DR (2005) Commercialization and implementation of biocontrol. Ann Rev Phytopathol 43:A337-A359

From C, Hormazabal V, Granum PE (2007) Food poisoning associated with pumilacidin-producing Bacillus pumilus in rice. Int J Food Microbiol 115(3):319-324

Frueh DP, Arthanari H, Koglin A, Vosburg DA, Bennett AE, Walsh CT, Wagner G (2008) Dynamic thiolation-thioesterase structure of a non-ribosomal peptide synthetase. Nature 454:903-906

Fujikawa K, Suketa Y, Hayashi K, Suzuki T (1965) Chemical structure of circulin A. Experientia 21(6):307-308

Garner BL, Arceneaux JEL, Byers BR (2004) Temperature control of a 3,4-dihydroxybenzoate (protocatechuate)based siderophore in Bacillus anthracis. Curr Microbiol 49(2):89-94

Gerard JM, Haden P, Kelly MT, Andersen RJ (1999) Loloatins A-D, cyclic decapeptide antibiotics produced in culture by a tropical marine bacterium. J Nat Prod 62(1):80-85

Grangemard I, Bonmatin JM, Bernillon J, Das BC, Peypoux F (1999) Lichenysin G, novel family of lipopeptide 
biosurfactants from Bacillus licheniformis IM 1307: production, isolation and structural evaluation by NMR and mass spectrometry. J Antibiot 52:363-373

Grangemard I, Wallach J, Maget-Dana R, Peypoux F (2001) Lychenysin: a more efficient cation chelator than surfactin. Appl Biochem Biotechnol 90(3):199-210

Hagelin G (2005a) Structure investigation of maltacine B1a, B1b, B2a and B2b: cyclic peptide lactones of the maltacine complex from Bacillus subtilis. J Mass Spectrom 40(4): $527-538$

Hagelin G (2005b) Structure investigation of maltacine C1a, $\mathrm{C} 1 \mathrm{~b}, \mathrm{C} 2 \mathrm{a}$ and $\mathrm{C} 2 \mathrm{~b}$ : cyclic peptide lactones of the maltacine complex from Bacillus subtilis. J Mass Spectrom 40(10): $1276-1286$

Hagelin G (2005c) Structure investigation of maltacine D1a, D1b and D1c: cyclic peptide lactones of the maltacine complex from Bacillus subtilis. J Mass Spectrom 40(10): 1287-1299

Hagelin G (2005d) Mass spectrometric investigation of maltacines E1a and E1b-2 members of the maltacine family of peptide antibiotics. Rapid Commun Mass Spectrom 19(24): 3633-3642

Hagelin G, Indrevoll B, Hoeg-Jensen T (2007) Use of synthetic analogues in confirmation of structure of the peptide antibiotics maltacines. Int J Mass Spectrom 268:254-264

Hamdache A, Lamarti A, Aleu J, Collado IG (2011) Non-peptide metabolites from the genus Bacillus. J Nat Prod 74: 893-899

Hancock REW, Chapple DS (1999) Peptide antibiotics. Antimicrob Agents Chemother 43(6):1317-1323

Harnois I, Maget-Dana R, Ptak M (1989) Methylation of the antifungal lipopeptide iturin A modifies its interaction with lipids. Biochimie 71(1):111-116

Harwood CR (1992) Bacillus subtilis and its relatives: molecular biological and industrial workhorses. Trends Biotechnol 10:247-256

Harwood CR, Cranenburgh R (2008) Bacillus protein secretion: an unfolding story. Trends Microbiol 16:73-79

Hasumi K, Takizawa K, Takahashi F, Park JK, Endo A (1995) Inhibition of Acyl-CoA: cholesterol acyltransferase by isohalobacillin, a complex of novel cyclic acylpeptides produced by Bacillus sp. A1238. J Antibiot 48(12):1419-1424

Hathout Y, Ho Y-P, Ryzhov V, Demirev P, Fenselau C (2000) Kurstakins: a new class of lipopeptides isolated from Bacillus thuringiensis. J Nat Prod 63(11):1492-1496

He J, Shao X, Zheng H, Li M, Wang J, Zhang Q, Li L, Liu Z, Sun M, Wang S, Yu Z (2010) Complete genome sequence of Bacillus thuringiensis mutant strain BMB171. J Bacteriol 192:4074-4075

Hecker M, Voelker U (2004) Towards a comprehensive understanding of Bacillus subtilis cell physiology by physiological proteomics. Proteomics 4:3727-3750

Helgason E, Caugant DA, Olsen I, Kolsto A-B (2000) Genetic structure of population of Bacillus cereus and B. thuringiensis isolates associated with periodontitis and other human infections. J Clin Microbiol 38:1615-1622

Hirata F, Axelrod J (1980) Phospholipid methylation and biological signal transmission. Science 209:1082-1090

Hoffmaster AR, Ravel J, Rasko DA, Chapman GD, Chute MD, Marston CK, De BK, Sacchi CT, Fitzgerald C, Mayer LW et al (2004) Identification of anthrax toxin genes in a Bacillus cereus associated with an illness resembling inhalation anthrax. Proc Natl Acad Sci USA 101:8449-8454

Hong HA, Duc L-H, Cutting SM (2005) The use of bacterial spore formers as probiotics. FEMS Microbiol Rev 29:813-835

Hu X, Boyer GL (1995) Isolation and characterization of the siderophore N-deoxyschizokinen from Bacillus megaterium ATCC 19213. Biometals 8(4):357-364

$\mathrm{Hu}$ X, Boyer GL (1996) Siderophore-mediated aluminum uptake by Bacillus megaterium ATCC 19213. Appl Environ Microbiol 62(11):4044-4048

Hunt A, Rawlins JP, Thomaides HB, Errington J (2006) Functional analysis of 11 putative essential genes in Bacillus subtilis. Microbiology 152:2895-2907

Idriss EE, Makarewicz O, Farouk A, Rosner K, Greiner R, Bochow H, Richter T, Borriss R (2002) Extracellular phytase activity of Bacillus amyloliquefaciens FZB45 contributes to its plant-growth-promoting effect. Microbiology 148:2097-2109

Ito T (1993) Enzymatic determination of itoic acid, a Bacillus subtilis siderophore, and 2,3-dihydroxybenzoic acid. Appl Environ Microbiol 59(7):2343-2345

Ivanova N, Sorokin A, Anderson I, Galleron N, Candelon B, Kapatral V, Bhattacharyya A, Reznik G, Mikhailova N, Lapidus A et al (2003) Genome sequence of Bacillus cereus and comparative analysis with Bacillus anthracis. Nature 423:87-91

Jedrzejas MJ, Huang WJM (2003) Bacillus species proteins involved in spore formation and degradation: from identification in the genome, to sequence analysis, and determination of function and structure. Crit Rev Biochem Mol Biol 38:173-198

Jenny K, Deltrieu V, Kappeli O (1993) Lipopeptide production by Bacillus licheniformis. In: Kosaric N (ed) Biosurfactants. Dekker, Inc, New York, pp 135-156

Jourdan E, Henry G, Duby F, Dommes J, Barthelemy JP, Thonart P, Ongena M (2009) Insights into the defenserelated events occurring in plant cells following perception of surfactin-type lipopeptide from Bacillus subtilis. Mol Plant Microbe Interact 22:456-468

Kajimura Y, Kaneda M (1997) Fusaricidins B, C and D, new depsipeptide antibiotics produced by Bacillus polymyxa KT-8: isolation, structure elucidation and biological activity. J Antibiot 50(3):220-228

Kajimura Y, Sugiyama M, Kaneda M (1995) Bacillopeptins, new cyclic lipopeptide antibiotics from Bacillus subtilis FR-2. J Antibiot 48(10):1095-1103

Kameda Y, Oira S, Matsui K, Kanatomo S, Hase T (1974) Antitumor activity of Bacillus natto V. Isolation and characterization of surfactin in the culture medium of Bacillus natto KMD 2311. Chem Pharm Bull 22:938-944

Kaminski K, Sokolowska T (1973) Probable identity of bacilysin and tetaine. J Antibiot 26(3):184-185

Kaneda M, Kajimura Y (2002) New antifungal antibiotics, bacillopeptins and fusaricidins. Yakugaku Zasshi-J Pharm Soc Jpn 122(9):651-671

Kato T, Shoji J (1976) Studies on antibiotics from the genus Bacillus. XIX. The amino acid sequence of octapeptin C1 (333-25). J Antibiot 29(12):1339-1340

Kato T, Shoji J (1980) Studies on antibiotics from the genus Bacillus. XXVIII. The structure of octapeptin D. J Antibiot 33(2):186-191 
Kato T, Hinoo H, Shoji J (1978) Studies on antibiotics from the genus Bacillus. XXIV. The structure of tridecaptin A. J Antibiot 31(7):652-661

Kato T, Sakazaki R, Hinoo H, Shoji J (1979) Studies on antibiotics from the genus Bacillus. XXV. The structures of tridecaptins B and C. J Antibiot 32(4):305-312

Keim P, Gruendike JM, Klevytska AM, Schupp JM, Challacombe J, Okinaka R (2009) The genome and variation of Bacillus anthracis. Mol Aspects Med 30:397-405

Kelkar DA, Chattopadhyay A (2007) The gramicidin ion channel: a model membrane protein. Biochim Biophys Acta 1768: 2011-2025

Kevany BM, Rasko DA, Thomas MG (2009) Characterization of the complete zwittermicin A biosynthesis gene cluster from Bacillus cereus. Appl Environ Microbiol 75(4): 1144-1155

Kherat DM, Maksimov VN, Zharikova GG (1974) Optimization of the medium for the biosynthesis of esein and bresein using a mathematical experiment design. Biol Nauki 17(1):90-94

Kikuchi T, Hasumi K (2002) Enhancement of plasminogen activation by surfactin $C$ : augmentation of fibrinolysis in vitro and in vivo. Biochim Biophys Acta 1596(2):234-245

Kim SD, Park SK, Chon JY, Park HJ, Lim JH, Yun HI, Park SC, Lee KY, Kim SK, Rhee MH (2006) Surfactin C inhibits platelet aggregation. J Pharm Pharmacol 58(6):867-870

Kimura Y, Murai E, Fujisawa M, Tatsuki T, Nobue F (1969) Polymyxin $\mathrm{P}$, a new antibiotic of the polymyxin group. J Antibiot 22(9):449-450

King TP, Craig LC (1955) The chemistry of tyrocidine. V. The amino acid sequence of tyrocidine B. J Am Chem Soc 77:6627-6631

Kino K, Kotanaka Y, Arai T, Yagasaki M (2009) A novel L-amino acid ligase from Bacillus subtilis NBRC3134, a microorganism producing peptide-antibiotic rhizocticin. Biosci Biotechnol Biochem 73(4):901-907

Kline T, Holub D, Therrien J, Leung T, Ryckman D (2001) Synthesis and characterization of the colistin peptide polymixin E1 and related antimicrobial peptides. J Pept Res 57:175-187

Kloepper JW, Leong J, Teintze M, Schroth MN (1980) Enhanced plant growth by siderophores produced by plant growth-promoting rhizobacteria. Nature 286:885-886

Koeppe RE, Paczkowski JA, Whaley WL (1985) Gramicidin K, a new linear channel-forming gramicidin from Bacillus brevis. Biochemistry 24(12):2822-2826

Kondejewski LH, Farmer SW, Wishart D, Kay CM, Hancock REW, Hodges RS (1996) Modulation of structure and antibacterial and hemolytic activity by ring size in cyclic gramicidin S analogs. J Biol Chem 271:25261-25268

Konz D, Marahiel MA (1999) How do peptide synthetases generate structural diversity? Chem Biol 6:39-48

Konz D, Doekel S, Marahiel AM (1999) Molecular and biochemical characterization of the protein template controlling biosynthesis of the lipopeptide lichenysin. J Bacteriol 181:133-140

Koppisch AT, Browder CC, Moe AL, Shelley JT, Kinkel BA, Hersman LE, Iyer S, Ruggiero CE (2005) Petrobactin is the primary siderophore synthesized by Bacillus anthracis str. Sterne under conditions of iron starvation. Biometals 18:577-585
Kotan R, Dikbas N, Bostan H (2009) Biological control of post harvest disease caused by Aspergillus flavus on stored lemon fruits. Afr J Biotechnol 8:209-214

Koumoutsi A, Chen X-H, Henne A, Liesegang H, Hitzeroth G, Franke P, Vater J, Borriss R (2004) Structural and functional characterization of gene clusters directing nonribosomal synthesis of bioactive cyclic lipopeptides in Bacillus amyloliquefaciens strain FZB42. J Bacteriol 186:1084-1096

Koumoutsi A, Chen X-H, Vater J, Borriss R (2007) DegU and YczE positively regulate the synthesis of bacillomycin D by Bacillus amyloliquefaciens strain FZB42. Appl Environ Microbiol 73:6953-6964

Kracht M, Rokos H, Ozel M, Kowall M, Pauli G, Vater J (1999) Antiviral and hemolytic activities of surfactin isoforms and their methyl ester derivatives. J Antibiot 52:613-619

Kugler M, Loeffler W, Rapp C, Kern A, Jung G (1990) Rhizocticin A, an antifungal phosphono-oligopeptide of Bacillus subtilis ATCC 6633: biological properties. Arch Microbiol 153(3):276-281

Kunst F, Ogasawara N, Moszer I, Albertini AM, Alloni G, Azevedo V, Bertero MG, Bessieres P, Bolotin A, Borchert S, Borriss R, Boursier L, Brans A, Braun M, Brignell SC, Bron S, Brouillet S, Bruschi CV, Caldwell B, Capuano V, Carter NM, Choi SK, Codani JJ, Connerton IF, Danchin A et al (1997) The complete genome sequence of the grampositive bacterium Bacillus subtilis. Nature 390:249-256

Kuryło-Borowska Z, Szer W (1972) Inhibition of bacterial DNA synthesis by edeine. Effect on Escherichia coli mutants lacking DNA polymerase I. Biochim Biophys Acta 287:236-245

Lankford CE, Walker JR, Reeves JB, Nabbut NH, Byers BR, Jones RJ (1966) Inoculum-dependent division lag of Bacillus cultures and its relation to an endogenous factor(s) (Schizokinen). J Bacteriol 91(3):1070-1079

Lebbadi M, Gálvez A, Macqueda M, Martínez-Bueno M, Valdivia E (1994) Fungicin M-4 a narrow spectrum peptide antibiotic from Bacillus licheniformis M-4. J Appl Bacteriol 77:49-53

Leclere V, Bechet M, Adam A, Guez JS, Wathelet B, Ongena M, Thonart P, Gancel F, Chollet-Imbert M, Jacques P (2005) Mycosubtilin overproduction by Bacillus subtilis BBG100 enhances the organism's antagonistic and biocontrol activities. Appl Environ Microbiol 71:4577-4584

Lee BH, Miller MJ (1983) Natural ferric ionophores: total synthesis of schizokinen, schizokinen A, and arthrobactin. J Org Chem 48:24-31

Lee S-Ch, Kim S-H, Park I-H, Chung S-Y, Choi Y-L (2007) Isolation and structural analysis of bamylocin A, novel lipopeptide from Bacillusamyloliquefaciens LP03 having antagonistic and crude oil-emulsifying activity. Arch Microbiol 188(4):307-312

Li Y-M, Haddad NIA, Yang S-Z, Mu B-Z (2008) Variants of lipopeptides produced by Bacillus licheniformis HSN221 in different medium components evaluated by a rapid method ESI-MS. Int J Pept Res Ther 14:229-235

Loeffler W, Tschen JSM, Vanittanakom N, Kugler M, Knorpp E, Hsien T-F, Wu MS (1986) Antifungal effects of bacilysin and fengymycin from Bacillus subtilis F-29-3 A comparison with activities of other Bacillus antibiotics. J Phytopathol 115(3):204-213 
Logan NA, Popovic T, Hoffmaster A (2007) Bacillus and other aerobic endospore-forming bacteria. In: Murray PR (ed) Manual of clinical microbiology, 9th edn. ASM Press, Washington, DC, pp 455-473

Lugtenberg BJ, Kamilova F (2009) Plant-growth-promoting rhizobacteria. Annu Rev Microbiol 63:541-556

Maget-Dana R, Peypoux F (1994) Iturins, a special class of lipopeptides: biological and properties pore-forming physicochemical. Toxicology 87:151-174

Maget-Dana R, Thimon L, Peypoux F, Ptak M (1992) Surfactin/ iturin A interactions may explain the synergistic effect of surfactin on the biological properties of iturin A. Biochimie 74:1047-1051

Majumdar SK, Bose SK (1960) Amino acid sequence in mycobacillin. Biochem J 74:596-599

Makarasen A, Yoza K, Isobe M (2009) Higher structure of cereulide, an emetic toxin from Bacillus cereus, special comparison with valinomycin, an antibiotic from Streptomyces fulvissimus. Chem Asian J 4:688-698

Mannanov RN, Sattarova RK (2001) Antibiotics produced by Bacillus bacteria. Chem Nat Compd 37(2):117-123

Marahiel MA (1992) Multidomain enzymes involved in peptide synthesis. FEBS Lett 307:40-43

Marahiel MA, Nakano MM, Zuber P (1993) Regulation of peptide antibiotic production in Bacillus. Mol Microbiol 7(5):631-636

Marahiel MA, Stachelhaus T, Mootz HD (1997) Modular peptide synthetases involved in nonribosomal peptide synthesis. Chem Rev 97:2651-2673

Martin NI, Hu H, Moake MM, Churey JJ, Whittal R, Worobo RW, Vederas JC (2003) Isolation, structural characterization, and properties of mattacin (polymyxin M), a cyclic peptide antibiotic produced by Paenibacillus kobensis M. J Biol Chem 278(15):13124-13132

McAlpine JB, Bachmann BO, Piraee M, Tremblay S, Alarco A-M, Zazopoulos E, Farnet CM (2005) Microbial genomics as a guide to drug discovery and structural elucidation: ECO-02301, a novel antifungal agent, as an example. J Nat Prod 68:493-496

McIntosh JA, Donia MS, Schmidt EW (2009) Ribosomal peptide natural products: bridging the ribosomal and nonribosomal worlds. Nat Prod Rep 26:537-559

Meyers E, Parker WL, Brown WE, Shoji J, Wakisaka Y (1976) A nomenclature proposal for the octapeptin antibiotics. J Antibiot 29(11):1241-1242

Mhammedi A, Peypoux F, Besson F, Michel G (1982) Bacillomycin $\mathrm{F}$, a new antibiotic of iturin group: isolation and characterization. J Antibiot 35(3):306-311

Michener HD, Snell N (1949) Two antifungal substances from Bacillus subtilis cultures. Arch Biochem 22:208-214

Miethke M, Klotz O, Linne U, May JJ, Beckering CL, Marahiel MA (2006) Ferri-bacillibactin uptake and hydrolysis in Bacillus subtilis. Mol Microbiol 61(6):1413-1427

Ming L-J, Epperson JD (2002) Metal binding and structureactivity relationship of the metalloantibiotic peptide bacitracin. J Inorg Biochem 91:46-58

Mogi T, Kita K (2009) Gramicidin S and polymyxins: the revival of cationic cyclic peptide antibiotics. Cell Mol Life Sci 66(23):3821-3826
Moszer I (1998) The complete genome of Bacillus subtilis: from sequence annotation to data management and analysis. FEBS Lett 430:28-36

Moyne A-L, Cleveland TE, Tuzun S (2004) Molecular caracterization and analysis of the operon encoding the antifungal lipopeptide bacillomycin D. FEMS Microbiol Lett 234:43-49

Mulligan CN (2005) Environmental applications for biosurfactants. Environ Pollut 133:183-198

Mullis KB, Pollack JR, Neilands JB (1971) Structure of schizokinen, an iron-transport compound from Bacillus megaterium. Biochemistry 10(26):4894-4898

Murai A, Amino Y, Ando T (1985) Absolute configuration of the $\beta$-hydroxyl fatty acid constituent of permetin A. J Antibiot 38(11):1610-1613

Murray FJ, Tetrault PA, Kaufmann OW, Koffler H, Peterson DH, Colingsworth DR (1949) Circulin, an antibiotic from an organism resembling Bacillus circulans. J Bacteriol 57:305-312

Naruse N, Tenmyo O, Kobaru S, Kamei H, Miyaki T, Konishi M, Oki T (1990) Pumilacidin, a complex of new antiviral antibiotics: production, isolation, chemical properties, structure and biological activity. J Antibiot 43(3):267-280

Nett M, Ikeda H, Moore BS (2009) Genomic basis for natural product biosynthetic diversity in the actinomycetes. Nat Prod Rep 26:1362-1384

Newton GGF (1949) Antibiotics from a strain of Bacillus subtilis: bacilipin A and B and bacilysin. J Exp Pathol 30:306-319

Newton BA (1956) The properties and mode of action of the polymyxins. Bacteriol Rev 20:14-27

Nickerson KW, Schnell DJ (1983) Toxicity of cyclic peptide antibiotics to larvae of Aedes aegypti. J Invertebr Pathol 42:407-409

Nicolas JP (2003) Molecular dynamics simulation of surfactin molecules at the water hexane interface. Biophys J 85:1377-1391

Nishikiori T, Naganawa H, Muraoka Y, Aoyagi T, Umezawa H (1986a) Plipastatins: new inhibitors of phospholipase A2, produced by Bacillus cereus BMG302-fF67. III. Structural elucidation of plipastatins. J Antibiot 39:755-761

Nishikiori T, Naganawa H, Muraoka Y, Aoyagi T, Umezawa H (1986b) Plipastatins: new inhibitors of phospholipase A2, produced by Bacillus cereus BMG302-fF67. II. Structure of fatty acid residue and amino acid sequence. J Antibiot 39(6):745-754

Obrig T, Irvin J, Culp W, Hardesty B (1971) Inhibition of peptide initiation on reticulocyte ribosomes by edeine. Eur J Biochem 21:31-41

Ogawa H, Ito T (1951) Esperin, a new antibiotic. I. Properties and constitution of esperin. Nippon Nogei Kagaku Kaishi 24:191-196

Ollinger J, Song K-B, Antelmann H, Hecker M, Helmann JD (2006) Role of the fur regulon in iron transport in Bacillus subtilis. J Bacteriol 88(10):3664-3673

Oman TJ, van der Donk WA (2010) Follow the leader: the use of leader peptides to guide natural product biosynthesis. Nat Chem Biol 6:9-18

Ongena M, Jacques P (2008) Bacillus lipopeptides: versatile weapons for plant disease biocontrol. Trends Microbiol 16:115-125 
Otoguro K, Liu ZX, Fukuda K, Li Y, Iwai Y, Tanaka H, Omura $S$ (1988) Screening for new nematocidal substances of microbial origin by a new method using the pine wood nematode. J Antibiot 41:573-575

Park JK, Hasumi K, Endo A (1995) Inhibition of the binding of oxidized low density lipoprotein to the macrophages by iturin C-related compounds. J Antibiot 48(3):226-232

Parker WL, Rathnum ML (1975) EM49, a new peptide antibiotic. IV. Structure of EM49. J Antibiot 28(5):379-389

Parker WL, Rathnum ML, Dean LD, Nimeck MW, Brown WE, Meyers E (1977) Polymyxin F, a new peptide antibiotic. J Antibiot 30:767-769

Pavli V, Kmetec V (2006) Pathways of chemical degradation of polypeptide antibiotic bacitracin. Biol Pharm Bull 29(11): 2160-2167

Pereira de Melo FM, Fiore MF, Beraldo de Moraes LA, SilvaStenico ME, Seramin Sh, Teixeira MA, Soares de Melo I (2009) Antifungal compound produced by the cassava endophyte Bacillus pumilus MAIIIM4A. Sci Agric 66(5): 583-592

Peypoux F, Guinand M, Michel G, Delcambe L, Das BC, Lederer E (1978a) Structure of iturin A, a peptidolipid antibiotic from Bacillus subtilis. Biochemistry 17:3992-3996

Peypoux F, Besson F, Michel G, Delcambe L, Das BC (1978b) Structure de l'iturin $\mathrm{C}$ de Bacillus subtilis. Tetrahedron 34:1147-1152

Peypoux F, Besson F, Michel G, Delcambe L (1981) Structure of bacillomycin D, a new antibiotic of the iturin group. Eur J Biochem 118:323-327

Peypoux F, Marion D, Maget-Dana R, Ptak M, Das BC, Michel G (1985) Structure of bacillomycin F, a new peptidolipid antibiotic of the iturin group. Eur J Biochem 153:335-340

Peypoux F, Pommier MT, Marion D, Ptak M, Das BC, Michel G (1986) Revised structure of mycosubtilin, a peptidolipid antibiotic from Bacillus subtilis. J Antibiot 39(5):636-641

Pfaender P, Specht D, Heinrich G, Schwarz E, Kuhnle E, Simlot MM (1973) Enzymes of Bacillus licheniformis in the biosynthesis of bacitracin A. FEBS Lett 32(1):100-104

Pfleger BF, Nusca T, Scaglione JB, Sherman DH (2009) Petrobactin biosynthesis: a target for antibiotics against anthrax. Abstracts of Papers, 238th ACS National Meeting, Washington, DC, United States

Pichard B, Larue J-P, Thouvenot D (1995) Gavaserin and saltavalin, new peptide antibiotics produced by Bacillus polymyxa. FEMS Microbiol Lett 133(3):215-218

Plowman JE, Loehr TM, Goldman SJ, Sanders-Loehr J (1984) Structure and siderophore activity of ferric schizokinen. J Inorg Biochem 20(3):183-197

Posfay-Barbe KM, Schrenzel J, Frey J, Studer R, Korff C, Belli DC, Parvex P, Rimensberger PC, Schappi MG (2008) Food poisoning as a cause of acute liver failure. Pediatr Infect Dis J 27:846-847

Priest F (1993) Systematics and ecology of Bacillus. In: Sonenshein AL, Hoch JA, Losick R (eds) Bacillus subtilis and other Gram-positive bacteria. ASM Press, Washington, DC, pp 3-16

Pueyo MT, Bloch C Jr, Carmona-Ribeiro AM, Mascio P (2009) Lipopeptides produced by a soil Bacillus megaterium strain. Microb Ecol 57(2):367-378

Raaijmakers JM, De Bruijn I, Nybroe O, Ongena M (2010) Natural functions of lipopeptides from Bacillus and
Pseudomonas: more than surfactants and antibiotics. FEMS Microbiol Rev 34:1037-1062

Radnedge L, Agron PG, Hill KK, Jackson PJ, Ticknor LO, Keim P, Andersen GL (2003) Genome differences that distinguish Bacillus anthracis from Bacillus cereus and Bacillus thuringiensis. Appl Environ Microbiol 69:2755-2764

Radzhapov RA, Zharikova GG, Silaev AB, Katrukha GS (1968) Amino acid composition and physical-chemical properties of esein and bresein, new antibiotics from Bacillus brevis. Nauchnye Doki Vyss Shkoly Biol Nauki 3:99-102

Rahman MS, Ano T, Shoda M (2006) Second stage production of iturin A by induced germination of Bacillus subtilis RB14. J Biotechnol 125:513-515

Rapp C, Jung G, Katzer W, Loeffler W (1988a) Chlorotetaine from Bacillus subtilis, an antifungal dipeptide with an unusual chloro containing amino acid. Angew Chem 100(12): 1801-1802

Rapp C, Jung G, Kugler M, Loeffler W (1988b) Rhizocticinsnew phosphono-oligopeptides with antifungal activity. Liebigs Ann Chem 7:655-661

Rasko DA, Altherr MR, Han CS, Ravel J (2005) Genomics of the Bacillus cereus group of organisms. FEMS Microbiol Rev 29:303-329

Raubitschek F, Dostrovsky A (1950) An antibiotic active against dermatophytes, derived from Bacillus subtilis. Dermatologica 100:45-49

Ravel J, Fraser CM (2005) Genomics at the genus scale. Trends Microbiol 13:95-97

Raza W, Wu H, Shah MAA, Shen Q (2008) A catechol type siderophore, bacillibactin: biosynthesis, regulation and transport in Bacillus subtilis. J Basic Microbiol 48:1-12

Razafindralambo H, Popineau Y, Deleu M, Hbid C, Jacques P, Thonart P, Paquot M (1998) Foaming properties of lipopeptides produced by Bacillus subtilis: effect of lipid and peptide structural attributes. J Agric Food Chem 46:911-916

Read TD, Salzberg SL, Pop M, Shumway M, Umayam L, Jiang L, Holtzapple E, Busch JD, Smith KL, Schupp JM, Solomon D, Keim P, Fraser CM (2002) Comparative genome sequencing for discovery of novel polymorphisms in Bacillus anthracis. Science 296:2028-2033

Read TD, Peterson SN, Tourasse N, Baillie LW, Paulsen IT, Nelson KE, Tettelin H, Fouts DE, Eisen JA, Gill SR et al (2003) The genome sequence of Bacillus anthracis Ames and comparison to closely related bacteria. Nature 423: $81-86$

Rey MW, Ramaiya P, Nelson BA, Brody-Karpin SD, Zaretsky EJ, Tang M, Lopez de Leon A, Xiang H, Gusti V, Clausen IG, Olsen PB, Rasmussen MD, Andersen JT, Jorgensen PL, Larsen TS, Sorokin A, Bolotin A, Lapidus A, Galleron N, Ehrlich SD, Berka RM (2004) Complete genome sequence of the industrial bacterium Bacillus licheniformis and comparisons with closely related Bacillus species. Genome Biol 5(10):R77.1-R77.12

Rogers HJ, Lomakina N, Abraham EP (1965) Structure of bacilysin. Biochem J 97(2):579-586

Romano A, Vitullo D, Di Pietro A, Lima G, Lanzotti V (2011) Antifungal lipopeptides from Bacillus amyloliquefaciens strain BO7. J Nat Prod 74:145-151

Rosenberg E, Ron EZ (1999) High- and low-molecular-mass microbial surfactants. Appl Microbiol Biotechnol 52: 154-162 
Saeki K, Ozaki K, Kobayashi T, Ito S (2007) Detergent alkaline proteases: enzymatic properties, genes, and crystal structures. J Biosci Bioeng 103:501-508

Schneider R, Hantke K (1993) Iron-hydroxamate uptake systems in Bacillus subtilis: identification of a lipoprotein as part of a binding protein-dependent transport system. Mol Microbiol 8(1):111-121

Schnepf E, Crickmore N, Van Rie J, Lereclus D, Baum J, Feitelson J, Zeigler DR, Dean DH (1998) Bacillus thuringiensis and its pesticidal crystal proteins. Microbiol Mol Biol Rev 62:775-806

Schoenafinger G, Marahiel MA (2009) Nonribosomal peptides: biosynthesis. Wiley Encyclopedia Chem Biol 3:432-440

Senghor A, Liang WL, Ho W (2007) A mutant of Bacillus subtilis strain LB5 with enhanced antifungal activities against Colletotrichum gloeosporioides. Biocontrol Sci Technol 9:575-580

Seydlova G, Svobodova J (2008) Review of surfactin chemical properties and the potential biomedical applications. Cent Eur J Med 3:123-133

Sheng G-Y-W, Makoto K, Kaoru Y, Kazunaga Y, Daisuke U (1995) Homocereulide, an extremely potent cytotoxic depsipeptide from the marine bacterium Bacillus cereus. Chem Lett 9:791-792

Shoda M (2000) Bacterial control of plant diseases. J Biosci Bioeng 89(6):515-521

Shoji J (1978) Recent chemical studies on peptide antibiotics from the genus Bacillus. Adv Appl Microbiol 18:187-214

Shoji J, Hinoo H (1975) Antibiotics from the genus Bacillus. II. Chemical characterization of new antibiotics, cerexins A and B. J Antibiot 28:60-63

Shoji J, Kato T (1976a) Studies on antibiotics from the genus Bacillus. X. The structure of brevistin. J Antibiot 29(4): 380-389

Shoji J, Kato T (1976b) Studies on antibiotics from the genus Bacillus. XVII. The structure of cerexin B. J Antibiot 29: 1275-1280

Shoji J, Sakazaki R, Wakisaka Y, Koizumi K, Mayama M, Matsuura S, Matsumoto K (1976a) Studies on antibiotics from the genus Bacillus. IX. Isolation of brevistin, a new peptide antibiotic. J Antibiot 29:375-379

Shoji J, Hwoo H, Wakisaka Y, Koizumi K, Mayama M, Matsuura S, Matsumoto K (1976b) Isolation of a new antibiotic 333-25, related to antibiotic EM49 (Studies on antibiotics from the genus Bacillus. XI). J Antibiot 29: $516-520$

Shoji J, Hinoo H, Wakisaka Y, Koizumi K, Mayama M, Matsuura S, Matsumoto K (1976c) Studies on antibiotics from the genus Bacillus. VIII. Isolation of three new antibiotics, thiocillins I, II and III, related to micrococcin P. J Antibiot 29(4):366-374

Shoji J, Kato T, Sakazaki R (1976d) Studies on antibiotics from the genus Bacillus. XVI. The total structure of cerexin A. J Antibiot 29(12):1268-1274

Shoji J, Kato T, Matsumoto K, Takahashi Y, Mayama M (1976e) Studies on antibiotics from the genus Bacillus. XVIII. Production and isolation of cerexins C and D. J Antibiot 29(12):1281-1285

Shoji J, Kato T, Hinoo H (1977a) The structures of two new polymyxin group antibiotics. J Antibiot 30(5):427-429
Shoji J, Kato T, Hinoo H (1977b) The structure of polymyxin S. (Studies on antibiotics from the genus Bacillus. XXI). J Antibiot 30(12):1035-1041

Shoji J, Kato T, Terabe S, Konaka R (1979) Studies on antibiotics from the genus Bacillus. XXVI. Resolution of peptide antibiotics, cerexins and tridecaptins, by high performance liquid chromatography. J Antibiot 32(4):313-319

Shoji J, Kato T, Yoshimura Y, Tori K (1981) Structural studies on thiocillins I, II and III (Studies on antibiotics from the genus Bacillus. XXIX). J Antibiot 34(9):1126-1136

Siefert JL, Larios-Sanz M, Nakamura LK, Slepecky RA, Paul JH, Moore ER, Fox GE, Jurtshuk P Jr (2000) Phylogeny of marine Bacillus isolates from the Gulf of Mexico. Curr Microbiol 41:84-88

Slepecky R, Hemphill E (2006) The genus Bacillus. Nonmedical. In: Dworkin M, Falkow S, Rosenberg E, Schleifer K-H, Stackebrandt E (eds) The prokaryotes, vol 4. Springer, New York, pp 530-562

Sogn JA (1976) Structure of the peptide antibiotic polypeptin. J Med Chem 19(10):1228-1231

Solaiman D (2005) Applications of microbial biosurfactants. Inform 16:408-410

Somers E, Vanderleyden J, Srinivasan M (2004) Rhizosphere bacterial signalling: a love parade beneath our feet. Crit Rev Microbiol 30:205-240

Stein T (2005) Bacillus subtilis antibiotics: structures, syntheses and specific functions. Mol Microbiol 56(4):845-857

Steinborn G, Hajirezaei M-R, Hofemeister J (2005) BAC genes for recombinant bacilysin and anticapsin production in Bacillus host strains. Arch Microbiol 183(2):71-79

Stewart CR, Casjens SR, Cresawn SG, Houtz JM, Smith AL, Ford ME, Peebles CL, Hatfull GF, Hendrix RW, Huang WM, Pedulla ML (2009) The genome of Bacillus subtilis Bacteriophage SPO1. J Mol Biol 388:48-70

Storm DR, Rosenthal KS, Swanson PE (1977) Polymyxin and related peptide antibiotics. Annu Rev Biochem 46: $723-763$

Sugawara K, Konishi M, Kawaguchi H (1984) BMY-28160, a new peptide antibiotic. J Antibiot 37(10):1257-1259

Sun L, Lu Z, Bie X, Lu F, Yang S (2006) Isolation and characterization of a co-producer of fengycins and surfactins, endophytic Bacillus amyloliquefaciens ES-2, from Scutellaria baicalensis Georgi. World J Microbiol Biotechnol 22(12):1259-1266

Takami H, Nakasone K, Takaki Y, Maeno G, Sasaki R, Masui N, Fuji F, Hirama C, Nakamura Y, Ogasawara N, Kuhara S, Horikoshi K (2000) Complete genome sequence of the alkaliphilic bacterium Bacillus halodurans and genomic sequence comparison with Bacillus subtilis. Nucleic Acids Res 28:4317-4331

Takami H, Takaki Y, Chee GJ, Nishi S, Shimamura S, Suzuki H, Matsui S, Uchiyama I (2004) Thermoadaptation trait revealed by the genome sequence of thermophilic Geobacillus kaustophilus. Nucleic Acids Res 32:6292-6303

Takimura Y, Saeki K, Kobayashi T (2004) Preparation of Bacillus alkali proteasa and use of the enzyme for production of ferrichrome. Jpn. Kokai Tokkyo Koho JP 2004065171

Tamaki M, Kokuno M, Sasaki I, Suzuki Y, Iwama M, Saegusa K, Kikuchi Y, Shindo M, Kimura M, Uchida Y (2009) 
Syntheses of low-hemolytic antimicrobial gratisin peptides. Bioorg Med Chem Lett 19(10):2856-2859

Temirov YV, Esikova TZ, Kashparov IA, Balashova TA, Vinokurov LM, Alakhov YB (2003) A catecholic siderophore produced by the thermoresistant Bacillus licheniformis VK21 strain. Russ J Bioorg Chem 29:542-549

Tendulkar SR, Saikumari YK, Patel V, Raghotama S, Munshi TK, Balaram P, Chattoo BB (2007) Isolation, purification and characterization of an antifungal molecule produced by Bacillus licheniformis BC98, and its effect on phytopathogen Magnaporthe grisea. J Appl Microbiol 103(6):2331-2339

Thimon L, Peypoux F, Wallach J, Michel G (1995) Effect of the lipopeptide antibiotic, iturin A, on morphology and membrane ultrastructure of yeast cells. FEMS Microbiol Lett 128(2):101-106

Thomas DW, Ito T (1969) Determination of amino acid sequences in oligopeptides by mass spectrometry. XVI. Revised structure of the peptide antibiotic esperin, established by mass spectrometry. Tetrahedron 25(9):1985-1990

Tjalsma H, Noback MA, Bron S, Venema G, Yamane K, van Dijl JM (1997) Bacillus subtilis contains four closely related type I signal peptidases with overlapping substrate specificities: constitutive and temporally controlled expression of different sip genes. J Biol Chem 272:25983-25992

Toraya T, Maoka T, Tsuji H, Kobayashi M (1995) Purification and structural determination of an inhibitor of starfish oocyte maturation from a Bacillus sp. Appl Environ Microbiol 61:1799-1804

Touré Y, Ongena M, Jacques P, Guiro A, Thonart P (2004) Role of lipopeptides produced by Bacillus subtilis GA1 in the reduction of grey mould disease caused by Botrytis cinerea on apple. J Appl Microbiol 96:1151-1160

Trischman JA, Jensen PR, Fenical W (1994) Halobacillin: a cytotoxic cyclic acylpeptide of the iturin class produced by a marine Bacillus. Tetrahedron Lett 35(31):5571-5574

Tsuge K, Ano T, Shoda M (1996) Isolation of a gene essential for biosynthesis of the lipopeptide antibiotics plipastatin B1 and surfactin in Bacillus subtilis YB8. Arch Microbiol 165:243-251

Tsuge K, Ano T, Hirai M, Nakamura Y, Shoda M (1999) The genes degQ, pps, and lpa-8 (sfp) are responsible for conversion of Bacillus subtilis 168 to plipastatin production. Antimicrob Agents Chemother 43:2183-2192

Tuin AW, Grotenbreg GM, Spalburg E, De Neeling AJ, MarsGroenendijk RH, van der Marel GA, Noort D, Overkleeft HS, Overhand M (2009) Structural and biological evaluation of some loloatin $\mathrm{C}$ analogues. Bioorg Med Chem 17(17):6233-6240

Udwary DW, Zeigler L, Asolkar RN, Singan V, Lapidus A, Fenical W, Jensen PR, Moore BS (2007) Genome sequencing reveals complex secondary metabolome in the marine actinomycete Salinispora tropica. Proc Natl Acad Sci USA 104:10376-10381

Umezawa H, Aoyagi T, Nishikiori T, Okuyama A, Yamagishi Y, Hamada M, Takeuchi T (1986) Plipastatins: new inhibitors of phospholipase A2, produced by Bacillus cereus $\mathrm{BMG} 302-\mathrm{fF} 67$. I. Taxonomy, production, isolation and preliminary characterization. J Antibiot 39:737-744

Vaara MS, Vaara TI (2009) Polymyxin derivatives and uses thereof, including for the treatment of Gram-negative bacterial infections. US Patent US 2009215677
Vanittanakom N, Loeffler W, Koch U, Jung G (1986) Fengycin a novel antifungal lipopeptide antibiotic produced by Bacillus subtilis F-29-3. J Antibiot 39(7):888-901

Vater J (1986) Lipopeptides, an attractive class of microbial surfactants. Prog Colloid Polym Sci 72:12-18

Vater J, Kablitz B, Wilde C, Franke P, Mehta N, Cameotra SS (2002) Matrix-assisted laser desorption ionization-time of flight mass spectrometry of lipopeptide biosurfactants in whole cells and culture filtrates of Bacillus subtilis $\mathrm{C}-1$ isolated from petroleum sludge. Appl Environ Microbiol 68(12):6210-6219

Veith B, Herzberg C, Steckel S, Feesche J, Maurer KH, Ehrenreich P, Baeumer S, Henne A, Liesegang H, Merkl R, Ehrenreich A, Gottschalk G (2004) The complete genome sequence of Bacillus licheniformis DSM13, an organism with great industrial potential. J Mol Microbiol Biotechnol $7: 204-211$

Velasquez JE, van der Donk WA (2011) Genome mining for ribosomally synthesized natural products. Curr Opin Chem Biol 15:11-21

Vogler K, Studer RO (1966) The chemistry of the polymyxin antibiotics. Experientia 22:345-416

Vogt TCB, Schinzel S, Bechinger B (2003) Biosynthesis of isotopically labeled gramicidins and tyrocidins by Bacillus brevis. J Biomol NMR 26(1):1-11

Voigt B, Schweder T, Sibbald MJJB, Albrecht D, Ehrenreich A, Bernhardt J, Feesche J, Maurer KH, Gottschalk G, van Dijl JM, Hecker M (2006) The extracellular proteome of Bacillus licheniformis grown in different media and under different nutrient starvation conditions. Proteomics 6:268-281

Vollenbroich D, Pauli G, Ozel M, Vater J (1997a) Antimycoplasma properties and applications in cell culture of surfactin, a lipopeptide antibiotic from Bacillus subtilis. Appl Environ Microbiol 63:44-49

Vollenbroich D, Ozel M, Vater J, Kamp RM, Pauli G (1997b) Mechanism of inactivation of enveloped viruses by the biosurfactant surfactin from Bacillus subtilis. Biologicals 25:289-297

Volpon L, Besson F, Lancelin J-M (1999) NMR structure of active and inactive forms of the sterol-dependent antifungal antibiotic bacillomycin L. Eur J Biochem 264:200-210

Volpon L, Besson F, Lancelin J-M (2000) NMR structure of antibiotics plipastatins A and B from Bacillus subtilis inhibitors of phospholipase A2. FEBS Lett 485:76-80

Wallace BA (1986) Structure of gramicidin A. Biophys J 49: 295-306

Wallace BA (1998) Recent advances in the high resolution structures of bacterial channels: gramicidin A. J Struct Biol 121:123-141

Walsh CT (2008) The chemical versatility of natural-product assembly lines. Acc Chem Res 41:4-10

Weissman KJ, Mueller R (2008) Crystal structure of a molecular assembly line. Angew Chem Int Edit 47:8344-8346

Wilkinson S, Lowe LA (1966) Structures of the polymixins A and the question of identity with the polymixin M. Nature 212(5059):311

Williams RB, Henrikson JC, Hoover AR, Lee AE, Cichewicz RH (2008) Epigenetic remodeling of the fungal secondary metabolome. Org Biomol Chem 6:1895-1897

Wilson MK, Abergel RJ, Raymond KN, Arceneaux JEL, Byers BR (2006) Siderophores of Bacillus anthracis, Bacillus 
cereus, and Bacillus thuringiensis. Biochem Biophys Res Commun 348:320-325

Wipat A, Harwood CR (1999) The Bacillus subtilis genome sequence: the molecular blueprint of a soil bacterium. FEMS Microbiol Ecol 28(1):1-9

Wojciechowska H, Zgoda W, Borowski E, Dziegielewski K, Ulikowski S (1983) The antibiotic edeine. XII. Isolation and structure of edeine F. J Antibiot 36(7):793-798

Woo S-M, Woo JU, Kim S-D (2007) Purification and characterization of the siderophore from Bacillus licheniformis $\mathrm{K} 11$, a multifunctional plant growth-promoting rhizobacterium. Han'guk Misaengmul-Saengmyongkong Hakhoechi 35(2):128-134

Woynarowska B, Chmara H, Borowski E (1979) Differential mechanism of action of the antibiotic edeine on prokaryotic and eukaryotic organism points to new basis for selective toxicity. Drugs Exp Clin Res 5:181-186

Xu Y, Sugar IP, Krishna NR (1995) A variable target intensity restrained global optimization (VARTIGO) procedure for determining three-dimensional structures of polypeptides from NOESY data: application to gramicidin-S. J Biomol NMR 5:37-48

Yakimov MM, Timmis KN, Wray V, Fredrickson HL (1995) Characterization of a new lipopeptide surfactant produced by thermotolerant and halotolerant subsurface Bacillus licheniformis BAS50. Appl Environ Microbiol 61:1706-1713

Yakimov MM, Amro MM, Bock M, Boseker K, Fredrickson HL, Kessel DG, Timmis KN (1997) The potential of Bacillus licheniformis strains for in situ enhanced oil recovery. J Pet Sci Eng 18:147-160

Yakimov MM, Abraham W-R, Meyer H, Giuliano L, Golyshin PN (1999) Structural characterization of lichenysin A components by fast atom bombardment tandem mass spectrometry. Biochim Biophys Acta 1438:273-280

Yang S, Wei D, Mu B (2006) Determination of the amino acid sequence in a cyclic lipopeptide using MS with DHT mechanism. J Biochem Biophys Methods 68:69-74

Yang Z, Guo H, Zhang X (2008) Study on the control of peach postharvest diseases using Bacillus subtilis. China Fruits 23:35-38

Yoko T, Asao M, Yoshiyuki T, Masatsune K (1979) The structure of permetin A, a new polypeptin type antibiotic produced by Bacillus circulans. J Antibiot 32(2):121-129

Youssef N, Simpson DR, Duncan KE, McInerney MJ, Folmsbee M, Fincher T, Knapp RM (2007) In-situ biosurfactant production by injected Bacillus strains in a limestone petroleum reservoir. Appl Environ Microbiol 73(4): 1239-1247

Zeigler DR, Perkins JB (2009) The genus Bacillus. In: Goldman E, Green LH (eds) Practical handbook of microbiology, 2nd edn. The Ohio State University, Columbus, $\mathrm{OH}$, pp 309-337

Zharikova GG, Zarubina AP, Kherat DM, Myaskovskaya SP, Maksimov VN (1975) Formation of polypeptide antibiotics by spontaneous and induced mutants of Bacillus brevis var G.-B. Antibiot Ikh Produtsenty 163-186

Zhenzhen Z, Qiushuo W, Kaimei W, Kemp B, Changhong L, Yucheng G (2010) Study of the antifungal activity of Bacillus vallismortis ZZ185 in vitro and identification of its antifungal components. Bioresour Technol 101:292-297

Zhou Y, Choi YL, Sun M, Yu ZN (2008) Novel roles of Bacillus thuringiensis to control plant diseases. Appl Microbiol Biotechnol 80:563-572 